\title{
National Program Plan for Absorber Surfaces R\&D
}

\author{
Patrick J.Call
}
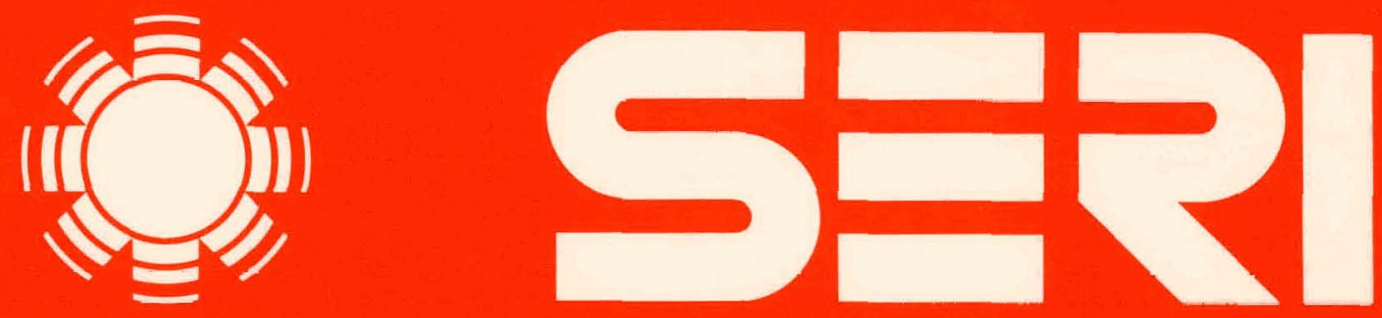

Solar Energy Research Institute A Division of Midwest Research Institute

1536 Cole Boulevard

Golden, Colorado 80401

Operated for the U.S. Department of Energy under Contract No. EG-77-C-01-4042

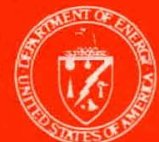




\section{DISCLAIMER}

This report was prepared as an account of work sponsored by an agency of the United States Government. Neither the United States Government nor any agency Thereof, nor any of their employees, makes any warranty, express or implied, or assumes any legal liability or responsibility for the accuracy, completeness, or usefulness of any information, apparatus, product, or process disclosed, or represents that its use would not infringe privately owned rights. Reference herein to any specific commercial product, process, or service by trade name, trademark, manufacturer, or otherwise does not necessarily constitute or imply its endorsement, recommendation, or favoring by the United States Government or any agency thereof. The views and opinions of authors expressed herein do not necessarily state or reflect those of the United States Government or any agency thereof. 


\section{DISCLAIMER}

Portions of this document may be illegible in electronic image products. Images are produced from the best available original document. 


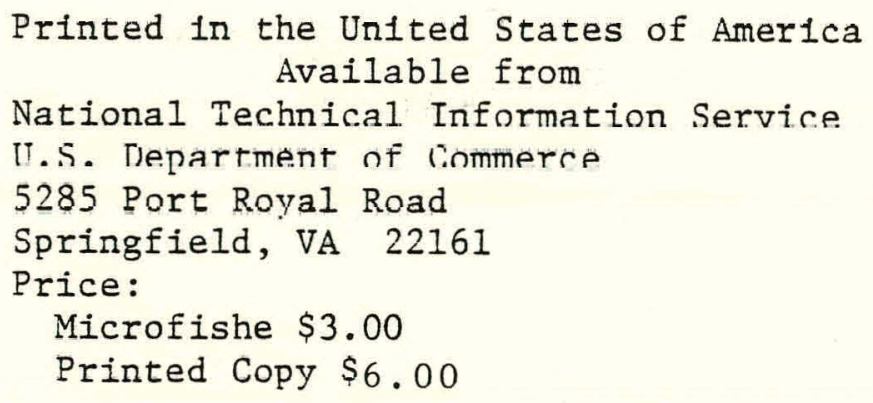

\section{NOTICE}

This report was prepared as an account of work sponsored by the United States Government. Neither the United States nor the United States Department of Energy, nor any of their employees, nor any of their contractors, subcontractors, or their employees, makes any warranty, express or implied, or assumes any legal liability or responsibility for the accuracy, completeness or usefulness of any information, apparatus, product or process disclosed, or represents that its use would not infringe privately owned rights. 


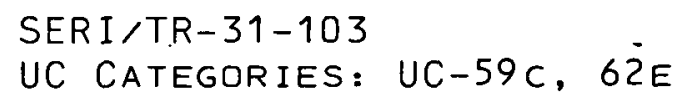

NATIONAL PROGRAM PLAN FOR ABSORBER SURFACES $R \quad \varepsilon \quad D$

PATRICK J. CALL

\section{JANUARY 1979}

\section{Solar Energy Research Institute}

1536 Cole Boulevard

Golden, Colorado 80401

A Division of Midwest Research Institute

Prepared for the

U.S. Department of Energy

Contract No. EG. $77 \cdot \mathrm{C} \cdot 01 \cdot 4042$ 


\section{SUMMARY}

The optical properties -- solar absorptance $\left(\boldsymbol{\alpha}_{\mathrm{S}}\right)$ and thermal emittance $\left(\boldsymbol{\epsilon}_{\mathrm{t}}\right)$ -- of the receiver surface are important in a wide range of solar energy conversion devices fron passive solar buildings to sophlsticated lwo axis tracking concentrators. This report describes a National Plan for Absorber. Surfaces $R \& D$ and includes the background information (available absorber materials and characteristics, applications, and probable benefits) used to derive the plan.

\section{S'I'A'L'E-OF-THE-ART ABSORBER SURFACES}

Some commercially available absorber materials are listed in Figure ]. with representative optical properties. Of these materials, electrodeposited black chrome dominates the low temperature selective absorber market $\left(\alpha_{s} \approx 0.95\right.$, $\left.\epsilon_{t} \approx 0.10\right)$. Electrodeposited black nickel with a protective overcoat to impede moisture penetration and electrodeposited black cobalt for applications to $400^{\circ} \mathrm{C}$ are also being produced. A number of nonselective $\left(\boldsymbol{\alpha}_{\mathrm{S}} \approx 1, \boldsymbol{\epsilon}_{t} \approx\right.$ $0.9)$ paints are commerci.ally available, including Pyromark which has undergone extensive tests as the baseline absorber surface for the Barstow, California lomwe pilot plant. Issues of concern to absorber surface users are not limited to optical performance and thermal stability as emphasized in Figure 2 .

\section{APPLICATIONS}

For purposes of comparison the receiver optical efficiency ( $\eta$ ) of a particular system can be described by a simplified expression

$$
\eta=\alpha_{3}-\beta \epsilon_{t}
$$

where $\beta$ is a measure of the importance of the receiver thermal emittance to the application and is the radiated heat flux of a blackbody at the system operating tempcrature $\left(\mathrm{T}_{1}\right)$ divided by the incoming solar flux delivered by the collector to the receiver surface. Figure 3 lists $\boldsymbol{\beta}$ for representative applications as a function of operating temperature and system concentration factor $\left(A_{c} / A_{r}\right)$.

\section{BENEFIT ANALYSIS}

This report describes a method for computing the benefit of absorber materials $R \& D$ based on performance and cost improvement of absorber surfaces referenced to the present state-of-the-art. The conservative calculation provides a guideline for programmatic emphasis based on the assumptions detailed in the text. As indicated in Figure 4, the present value of future benefits of absorber surface $R \& D$ can be very large. Low temperature absorber surfaces have highest priority, followed by absorber surfaces for parabolic troughs and 


\section{Properties of Selected Commercial Solar Absorber Surfaces}

\begin{tabular}{|c|c|c|c|c|c|}
\hline Material & Technique & $\begin{array}{l}\text { Supplier(S)/ } \\
\text { Developer(D) }\end{array}$ & $a_{s}$ & $\varepsilon_{t}(T)$ & $\underset{\left({ }^{\circ} \mathrm{C}\right)}{\text { T Stability** }}$ \\
\hline Black Chrome & electro-deposited & Many & $0.94-0.96$ & $\begin{array}{l}0.05-0.10(100) \\
0.20-0.25(300)\end{array}$ & 300 \\
\hline $\begin{array}{l}\text { Pyromark } \\
\text { S-31 } \\
\text { Nonselective }\end{array}$ & $\begin{array}{l}\text { paint } \\
\text { paint }\end{array}$ & $\begin{array}{l}\text { Tempil } \\
\text { Rockwell International }\end{array}$ & $\begin{array}{l}0.95 \\
0.8-0.85\end{array}$ & $\begin{array}{l}0.85(500) \\
0.8-0.85\end{array}$ & $\begin{array}{l}<750 \\
>550\end{array}$ \\
\hline $\begin{array}{l}\text { SOLARTEX } \\
\text { SOLAROX } \\
\text { (Proprietary) }\end{array}$ & $\begin{array}{l}\text { Electro-Deposited } \\
\text { " }\end{array}$ & $\underset{, " \text { Dornier (W. Germany) }}{ }$ & $\begin{array}{l}0.93-0.96 \\
0.92\end{array}$ & $\begin{array}{l}0.14-0.18(310) \\
0.20\end{array}$ & $\begin{array}{l}700 \\
200 .\end{array}$ \\
\hline Black Epoxy & Paint & Amicon Corp. & NA & NA & NA \\
\hline $436-3-8$ & " & Bostik (U.S.M. Corp.) & 0.90 & 0.92 & NA \\
\hline Enersorb & $"$ & Desoto & 0.96 & 0.92 & NA \\
\hline 7729 & $"$ & C. H. Hare & 0.96 & $0.90-0.92$ & NA \\
\hline R-412 & $"$ & Rusto-leum Co. & 0.95 & 0.87 & NA \\
\hline 5779 & $"$ & & 0.95 & 0.90 & NA \\
\hline $\begin{array}{l}\text { Nextel } \\
\text { (nanselective) }\end{array}$ & $"$ & 3-M & $0.97-0.98$ & $>0.90$ & 150 \\
\hline $\begin{array}{l}\text { NOVAMET } 150 \\
\text { (proprietary) }\end{array}$ & $"$ & Ergenics & 0.96 & 0.84 & $\begin{array}{l}800 \\
(1 \mathrm{hr})\end{array}$ \\
\hline MAXORB & (proprietary) & Ergenics & $0.97( \pm .01)$ & $0.10( \pm .03)$ & $\begin{aligned} & 150(20 \mathrm{wks}) \\
< & 400(1 \mathrm{hr})\end{aligned}$ \\
\hline $\begin{array}{l}\text { Tabor black } \\
\text { (NiS/ZnS) }\end{array}$ & $\begin{array}{l}\text { electrodeposited } \\
\text { \& overcoat }\end{array}$ & Miromit & 0.91 & 0.14 & - \\
\hline
\end{tabular}

Figure 1. 


\section{Issues of Concern for Absorber Surfaces}

- Operating Efficiency

High $a_{s}(T)$

Low $\varepsilon_{t}(T)$

Angle of incidence effects

High thermal conductivity

- Operating Life and Degradation Mechanisms

Temperature stability (maximum operating temperature, gradient, transients [shock], and cycling [fatigue])

Effects of solar photon flux (UV)

Impact and abrasion resistance (dust and hail)

Effect of adherent dust on optical properties

Chemical stability latmospheric, working fluid and

system contamination, rain, humidity)

Vacuum stability

- Repairability

- Cost/unit area

- Materials resource limitation or vulnerability

- Geometrical constraints in application of coating

- Shaping or forming after coating

- Limitations on substrate candidates

Figure 2. 


\section{Solar Thermal Systems*}

\begin{tabular}{|c|c|c|c|}
\hline System & $\mathrm{T}_{1}\left({ }^{\circ} \mathrm{C}\right)$ & $A_{c} / A_{r}$ & $\beta=\frac{\sigma\left(T_{1}{ }^{4}-T_{2}{ }^{4}\right)}{\phi T E p A_{c} / A_{1}}$ \\
\hline Passive & $25-80$ & 1 & $0-.7(\rho=1.0)$ \\
\hline Flat Plate & $40-180$ & 1 & $.13-3.7(\rho=1.0)$ \\
\hline Evacuated Tube (CPC, $V$ troughs) & $100-200$ & $1.5-3$ & $.5-3.3$ \\
\hline Linear Fresnel and Cylindrical Trough & $150-250$ & $6-10$ & $.3-1.3$ \\
\hline $\begin{array}{l}\text { Linear Parabolic \& Segmented Linear } \\
\text { Array Tracking System (SLATS) }\end{array}$ & $200-350$ & $20-70$ & $.07-.77$ \\
\hline Twvo Axis Tracking Fresnel & $200-350$ & $50-100$ & $.05-.3$ \\
\hline Spherical Reflector Tracking Absorber & $300-500$ & $100-200$ & $.06-.4$ \\
\hline Two Axis Tracking Parabolic Dish & $500-1100$ & 1000 & $<.04-3.5$ \\
\hline Central Receivers - Barstow $10 \mathrm{MWe}$ & 500 & 400 & .09 \\
\hline Steam Cycle (Ext. Rec.) 100 MWe & 500 & 1200 & .03 \\
\hline Adv. Molt. Salt \& Metal (Ext. Rec.) & 600 & $1800-2500$ & $.03-.04$ \\
\hline $\begin{array}{l}\text { Adv. Open \& Closed Adv. Brayton } \\
\text { Cycles (cavity receiver) }\end{array}$ & $1000-1400$ & $2500-4000$ & $.06-.3$ \\
\hline
\end{tabular}

Figure 3. 


\section{Summary of Benefits of Absorber Surface R\&D}

\begin{tabular}{llccc} 
System & $\Omega^{[1]}$ & $\Delta \eta / \eta^{[2]}$ & $\Delta \rho^{[3]}$ & $P V / \$ M)^{[4]}$ \\
$\begin{array}{l}\text { Flat Plate }\left(<100^{\circ} \mathrm{C}\right) \\
\text { Evacuated Tube } \\
\left(100-200^{\circ} \mathrm{C}\right)\end{array}$ & .35 & .04 & .03 & 390 \\
$\begin{array}{l}\text { Parabolic Trough } \\
\left(200^{\circ}-500^{\circ} \mathrm{C}\right)\end{array}$ & .45 & .04 & .03 & 160 \\
$\begin{array}{l}\text { Parabolic Dish } \\
\left(>500^{\circ} \mathrm{C}\right)\end{array}$ & .2 & .2 & 0 & 150 \\
$\begin{array}{l}\text { Small Central Receiver } \\
\left(500^{\circ} \mathrm{C}\right)\end{array}$ & .4 & .01 & 0 & 10 \\
$\begin{array}{l}\text { Large Central Receiver } \\
\left(500^{\circ} \mathrm{C}\right)\end{array}$ & .6 & $.05^{(2)}$ & 0 & 40 \\
\hline Total & .6 & $.01^{(2)}$ & 0 & 10 \\
\hline
\end{tabular}

[1] Average system thermal efficiency

[2] Relative improvement in receiver performance

[3] Absorber surface cost improvement (\% of total system cost)

[4] Present Value of Future Benefits of Absorber Surface Research 
higher temperature selective absorbers for low concentration ratio systems. Very high temperature materials have lowest priority. Absorbers for all applications require improved durability and further testing.

\section{NATIONAL PLAN FOR ABSORBER SURFACES R\&D}

\section{A. Objective}

The objective of the Absorber Surface $R \& D$ program is to assist the timely development of high performance, durable, and cost-effective solar absorbers for use in solar thermal systems through a cooperative government, industry, and university effort.

\section{B. Scope}

The program plan is projected for five years with maximum involvement of industry in the development projects. Universities and national laboratories will be used primarily in research and support activities. Based on the program benefit analysis an $\$ 8$ million program is outlined.

\section{Approach}

The program will lower front-end risks by providing research funds to demonstrate technical feasibility of absorber surface concepts. Cost sharing assistance in the developmental stage will provide further support. Commercial markets will be stimulated by identifying applications, certifying test procedures, and providing information.

\section{Overa11 Strategy}

The Absorber Surface $R \& D$ Program consists of program management, four development activities and four supporting functions.

The four developmental activities address: improved durability and costeffectiveness of low-temperature selective absorber surfaces for passive, flat-plate, and evacuated tube collectors to $200^{\circ} \mathrm{C}$; commercial black chrome and an identified alternate selective surface for applications to $400^{\circ} \mathrm{C}$; intermediate-temperature $\left(400-700^{\circ} \mathrm{C}\right)$ selective absorbers and absorber surfaces for high temperatures $\left(>700^{\circ} \mathrm{C}\right)$. The selection of temperature regimes for the goals is of necessity somewhat arbitrary. The choices were determined by adding an approximate $100^{\circ} \mathrm{C}$ buffer to operating temperatures for generic applications. Low-temperature surfaces are assumed to operate to $100^{\circ} \mathrm{C}$ based on cooling and process heat requirements, and the stagnation temperature for most low concentration ratio systems is approximately $200^{\circ} \mathrm{C}$. The $300^{\circ} \mathrm{C}$ operating temperature for black chrome is based on present single axis tracking system needs, and the transition from intermediate- to high-temperature regimes is based on the present materials limitation for the steam heat engine cycle $\left(560^{\circ} \mathrm{C}\right)$. 
The four supporting functions are: optical measurements, durability testing, and component evaluation; systems analysis; data base; and basic and generic research.

Estimates of the funding levels in constant FY78 dollars for these nine major activities are shown in Figure 5. Allocations will be based on the availability of funds.

LOW-COST SELECTIVE ABSORBERS (TO $200^{\circ} \mathrm{C}$ )

High-priority R\&D topics:

- reduce cost of absorber surfaces for flat plate collectors without redusing optir.al performanr.e or durahility;

- improve process control;

- assess availability of (and develop, if necessary) absorber materials for more cost-effective, second generation collector systems (evacuated tube, all plastic flat plates); and

- assess potential of selective absorbers for passive applications.

Long-range R\&D topic:

- increase solar absorptance from 0.95 to 0.98 , reduce thermal emittance from 0.1 to 0.05 without sacrificing cost or durability objectives.

BLACK CHROME (TO $400^{\circ} \mathrm{C}$ )

High-priority K\&l topics:

- establish reproducible processing techniques and identify key process parameters to achieve acceptable optical properties and thermal stability,

- investigate alternative black chrome electroplating solutions, and

- identify backup absorber surface.

Long Range $K \dot{\alpha L}$ topic:

improve solar absorptance to 0.98 while reducing thermal emittance. below 0.2 at $300^{\circ} \mathrm{C}$. 


\section{Overview of Estimated Program Funding (\$k)}

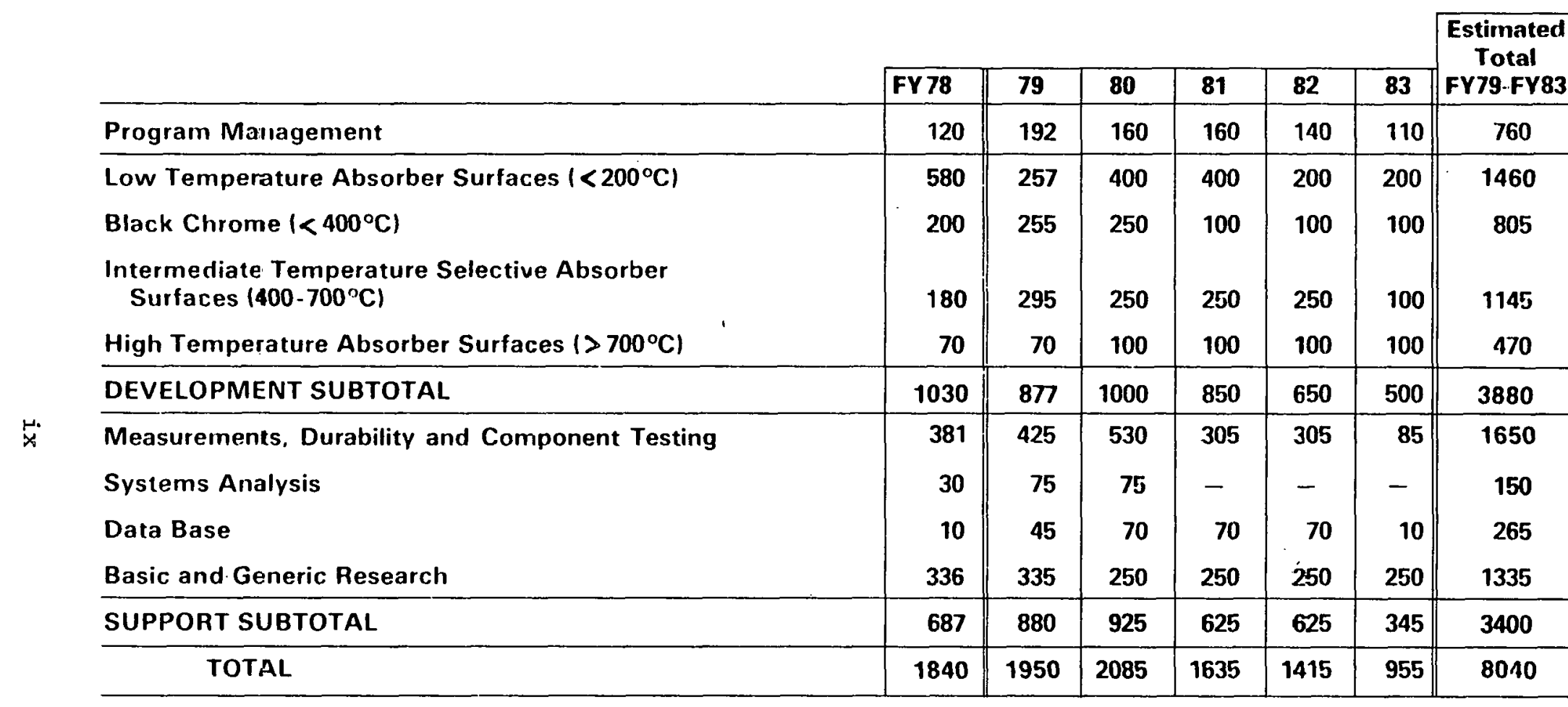

Figure 5 


\section{INTERMEDIATE-TEMPERATURE SELECTIVE SURFACES $\left(400^{\circ} \mathrm{C}\right.$ TO $\left.700^{\circ} \mathrm{C}\right)$}

High-priority R\&D topics:

- vacuum, CVD, or electrodeposition processing of foils and investigation of geometric limitations of applying foils, thermal conductance losses across bonding layer, availability of high-temperature bonding materials, and development of bonding techniques for on-site application. Vacuum-processed films (cermets, AMA-like interference stacks) have demonstrated promising optical properties and thermal stability so that the processing effort will be initiated using vacuum techniques to produce absorber surfaces.

- extend operating temperature range and optical properties of absorber surfaces that can be applied on-site (paints, chemical conversion surfaces, organometallics).

Long-range R\&D topics:

- determine degradation mechanisms of developmental absorber surfaces, and

- increase solar absorptance to greater than 0.97 through understanding of material limitations.

HIGH-TEMPERATURE COATINGS ( $\left.700^{\circ} \mathrm{C}\right)$

H1gh-priority R\&D Lopics:

- improved adhesion (thermal shock) and in situ curing,

- study of photothermal stability, and

- study of protection properties.

Long-range R\&D topic:

- stable, high-absorptance ( $\boldsymbol{\alpha}_{\mathrm{s}} \geq 0.98$ ) paints, plasma spray coatings and treated materials of construction.

OPTICAL MEASUREMENTS, DURABILITY TESTING, AND COMPONENT EVALUATION

Measured optical properties of absorber surfaces are required for the following purposes:

- engineering design,

- hardware verification and control,

- durability test evaluation, and

- coating development and analysis. 
The optical measurements support in the Absorber Surfaces Program consists of four activities:

- determination of appropriate optical measurements,

- development of standards to ensure that research measurements are comparable,

- identification or development of specialized optical measurement equipment where necessary, and

- independent measurement (qualification) of surfaces developed within the program.

Durability testing is required at three levels:

- testing at the research level by the developer to establish the inherent durability and to evaluate the effects of materials and/or process variations;

- testing at the program levcl (which includes basic research into mechanisms of degradation, in order to define accelerated lifetime tests) by an independent laboratory to corroborate the limits to coating utilization; and

- evaluation and qualification tests by the ultimate user.

\section{SYSTEMS ANALYSIS}

The systems analysis activity initiated by JPL in FY77 and FY78 will be retined and extended through a joint SERI/JPL effort. Major activities in FY79 will determine the minimum solar absorptance as a criterion in judging intermediate temperature selective absorber development, refine estimates of absorber surface and program cost/benefits, and determine the optimum optical properties for cavity absorbers.

\section{DATA BASE}

The data base activity is one part of a larger SERI priority program: the Solar Energy Information Data Base (SEIDB). The absorber surface portion of the materials data base serves two functions: (1) to make accessible to absorber surface developers and users state-of-the-art information on absorber surface performance, durability, and cost and (2) to provide a resource to the systems analysis and program management activities. 


\section{BASIC AND GENERIC RESEARCH}

The Basic and Generic Research activity will emphasize the understanding of degradation mechanisms (thermal, photothermal, environmental) and absorber modeling with a small budget reserved for innovative concepts. It is recognized that activities ongoing in DOE/Office of Basic Energy Science will provide a source of information while remaining independent of the Absorber Surfaces Program. 


\section{PREFACE}

This document was prepared under DOE Contract No. EG-77-C-01-4042, Task 3103, by Patrick J. Ca11, Materials Branch. The author wishes to express his gratitude for the support of the Materials Branch and in particular the branch chief, Barry Butler. Previous planning efforts by JPL provided a useful base for this document and discussions with $W$. Carroll are gratefully acknowledged.

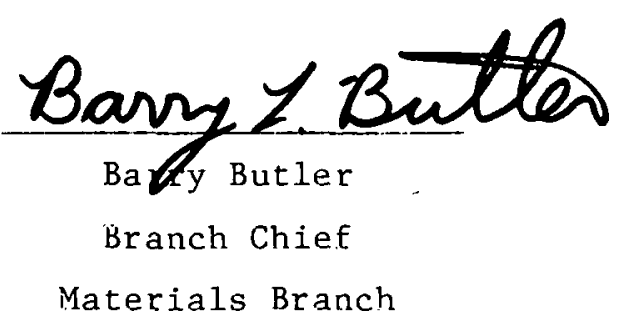

Approved for:

SOLAR ENERGY RESEARCH INSTITU'I'E

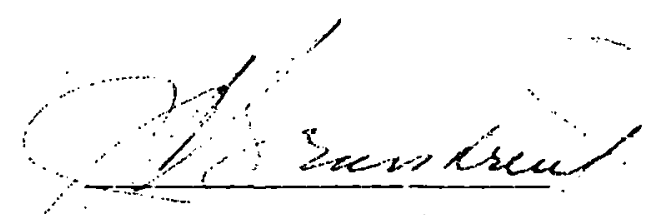

J. Charles Grosskreutz

Assitant Director

Research Division 
NOMENCLATURE

\begin{tabular}{|c|c|}
\hline$a_{s}$ & solar absorptance \\
\hline$\epsilon_{\mathrm{t}}$ & thermal emittance \\
\hline$\sigma$ & Stefan Boltzmann constant $\left(5.67 \times 10^{-8} \mathrm{~W} \mathrm{~m}^{-2}{ }^{\circ} \mathrm{K}^{-4}\right)$ \\
\hline $\mathrm{C}$ & solar transmittance \\
\hline$\phi$ & insolation \\
\hline$Q_{\text {conv }}$ & convective heat loss $\left(\mathrm{Wm}^{-2}\right)$ \\
\hline$Q_{\text {cond }}$ & conductive heat loss $\left(\mathrm{Wm}^{-2}\right)$ \\
\hline $\mathrm{T}$ & temperature \\
\hline$x$ & concentration factor \\
\hline$A_{c}$ & effective aperture area of concentrator mirror \\
\hline$A_{r}$ & illuminated area of receiver \\
\hline$E \equiv(1-e)$ & $\begin{array}{l}\text { e, fraction of energy lost due to mirror surface imperfections and } \\
\text { sun tracking errors. }\end{array}$ \\
\hline$\rho$ & mirror specular reflectance \\
\hline $\mathrm{MW}_{\mathrm{e}}$ & electrical megawatts \\
\hline${ }^{\circ} \mathrm{C}$ & degrees Celsius \\
\hline $\mathrm{m}$ & meter \\
\hline$\mu \mathrm{m}$ & micrometer $\left(10^{-6}\right.$ meter $)$ \\
\hline$\beta$ & $\begin{array}{l}\text { parameter measuring sensitivity of receiver efficiency to the } \\
\text { thermal emittance of the absorber surface }\end{array}$ \\
\hline$\eta(\Delta \eta)$ & receiver efficiency (change) \\
\hline$\xi$ & $\begin{array}{l}\text { measure of improved receiver efficiency due to improved absorber } \\
\text { surface optical properties }\end{array}$ \\
\hline PV & $\begin{array}{l}\text { present value of future benefits as a result of improved absorber } \\
\text { gurfacc }\end{array}$ \\
\hline$\Omega$ & system efficiency (sun light to thermal output) \\
\hline$v_{j n}$ & value of unit energy delivered by solar thermal system $j$ in year $n$ \\
\hline$E_{j n}$ & $\begin{array}{l}\text { quantity of energy delivered by system } j \text { in year } n \\
\text { percentage of capital cost }\end{array}$ \\
\hline$\ell$ & improvement in measured lifetime from current to expected \\
\hline $\mathrm{L}$ & expected absorber surface lifetime \\
\hline O\&M & operation and maintenance \\
\hline ET & Energy Technology \\
\hline
\end{tabular}




$\begin{array}{ll}\text { CS } & \text { Conservation and Solar Applications } \\ \text { OER/BES } & \text { Office of Energy Research/Basic Energy Sciences } \\ \text { SHAC } & \text { Solar Heating and Cooling } \\ \text { LASL } & \text { Los Alamos Scientific Laboratory } \\ \text { JPL } & \text { Jet Propulsion Laboratory } \\ \text { PRDA } & \text { Program R\&D announcement } \\ \text { FY } & \text { fiscal year } \\ \text { NIR-VIS-UV } & \text { near infrarcd-visible-ultraviolet (wavelength regions) }\end{array}$


TABLE OF CONTENTS

TITLE

PAGE

1.0 INTRODUCTION . . . . . . . . . . . . . . . 1

l.1 Background ................. 1

1.2 Objectives . . . . . . . . . . . . 3

1.3 Scope................. 4

1.4 Approach ................ 4

2.0 TECHNICAL ASSESSMENT . . . . . . . . . . . . 5

2.1 State-of-the-art Absorber Surfaces . . . . . 5

2.2 Applications ............... 14

2.3 Benefit Analysis ............. 17

2.4 Program Cost/Benefit . . . . . . . . . 28

2.5 Program Guidelines . . . . . . . . 32

3.0 NATIONAL PROGRAM PLAN ............ 35

3.1 Overall Strategy and Funding . . . . . . 35

3.2 Program Management . . . . . . . . . 35

3.3 Development and Demonstration ....... 37

3.4 Optical Measurements, Durability Testing and Component Evaluation ........ 45

3.5 Systems Analysis ........... 48

3.6 Data Base.............. . 48

3.7 Basic and Generic Research . . . . . . 48

4.0 SERI ABSORBER SURFACE ACTIVITIES . . . • • • . . 53

4.1 Degradation Mechanisms . . . . . . . . 53

4.2 Black Cobalt ............. . . 53

4.3 Benefit Analysis . . . . . . . . . 55

5.0 REFERENCES . . . . . . . . . . . . 57 
LIST OF FIGURES.

TITLE

PAGE

Figure 1-1 Active Solar Thermal Energy Conversion Devices . . 2

Figure 2-1 Receiver Thermal Efficiency . . . . . . . . 7

Figure 2-2 Optimum Spectral Reflectance of a Selective

Absorber Surface .............. 8

Figure 2-3 Isobenefit Contours for an Ideal Step Change

Absorber Surface Reflectance . . . . . . 19

Figure 2-4 Central Receiver Thermal Performance at $900^{\circ} \mathrm{C}$. 21

Figure 2-5 Central Receiver Performance at $536^{\circ} \mathrm{C}$. . . . 22

Figure 2-6 Parabolic Dish/Cavity Receiver Thermal.

Performance .............. 23

Figure 2-7 Parabolic Trough (E-W) Thermal Performance . . . 24

Figure 2-8 Market Penetration for Solar Heating, AIPH and

Solar Thermal Electric ........... 30

Figure 3-1 Overview of Estimated Program Funding . . . . 36

Figure 3-2 Funding for Identification and/or Development of

Low Cost Solar Absorbers for Passive, Flat Plate

and Evacuated Tube Receivers . . . . . . . . 39

Figure 3-3 Funding for Establishment of Commercial Viability

of Black Chrome for applications to $400^{\circ} \mathrm{C}$ and

Identification of an Alternate Absorber Surface • 41

Figure 3-4 Funding for Development of a Selective Absorber

for $400-700^{\circ} \mathrm{C}$ Applications .......... 42

Figure 3-5 Funding for Investigation of Thermophysical

Properties of High Temperature Receiver

Surfaces and Identification of Surfaces for

Temperatures Greater than $700^{\circ} \mathrm{C}$. . . . . . 44

Figure 3-6 Funding for Optical Measurements, Durability

Testing and Component Evaluation... . . . 46

Figure 3-7 Funding for Systems Analysis . . . . . . . . 49

Figure 3-8 Funding for Absorber Surface Data Base . . . . 50

Figure 3-9 Funding for Basic and Generic Research . . . . . 51

Figure 4-l Research and Support Activities for Absorber

Surfaces . . . . . . . . . . . . 54

Figure 4-2 Lines of Constant Percentage Improvement of

Solar Thermal System Efficiency as a Function of

Absorber Surface Optical Properties Relative to

a Gond Non-Selective Surface . . . . . . . 56 
LIST OF TABLES

TITLE

PAGE

Table 2-1 Generic Types of Selective Absorber Surfaces . . . . . 9

Table 2-2 Properties of Selected Solar Absorber Surfaces . . . . . 11

Table 2-3 Issues of Concern for Absorber Surfaces . . . . . . . 15

Table 2-4 Solar Thermal Systems . . . . . . . . . . . . . 16

Table 2-5 Receiver Performance Comparison for Selective vs.

Non-Selective Absorber Surfaces ......... 26

Table 2-6 Impact of Absorber System Cost on System Cost . . . . 27

Table 2-7 Summary of Benefits of Absorber Surface R \& D . . . . . 31

Table 2-8 Present DOE and National Laboratory Absorber

Surface Responsibilities . . . . . . . . . . . 33 


\section{ABSTRACT}

Numerous requirements are placed on absorber surfaces across the spectrum of solar thermal energy conversion systems. This report describes the adequacy of available absorber materials for a wide range of applications and derives a R\&D program plan from those systems which can benefit from improved receiver performance, cost or durability.

Four development activities are described in detail: improved selective absorbers to $200^{\circ} \mathrm{C}$, black chrome to $400^{\circ} \mathrm{C}$, selective absorbers to $700^{\circ} \mathrm{C}$, and absorber surfaces (optical and protective properties) above $700^{\circ} \mathrm{C}$. Identified support activities for the program are optical measurements, durability testing, component evaluation, systems analysis, data base, and basic research. 


\section{SECTION 1.0}

INTRODUCTION

\subsection{BACKGROUND}

A wide range of solar energy conversion devices from passive solar building design to sophisticated two-axis tracking concentrators are described in terms of common components: collector, heat exchanger, working fluid (heat transfer), storage, and control subsystems. The receiver as part of the collector subsystcm is common to all such systems, and the importance of its optical properties (solar absorptance and thermal emittance) is easily recognized. The solar absorptance is a primary factor in determining the fraction of solar energy incident on the collector that will be available as useful heat, and the thermal emittance controls the reradiation of thermal energy from the collector that may be a major loss mechanism for certain applications.

The receiver for a passive design might be a brick floor or a massive Trombe wall, and the absorbing surface is typically the material of construction itself or a black paint. Improvements in passive system performance may be achieved by utilizing inexpensive absorber surfaces with enhanced optical properties. Achieving higher temperatures from active solar thermal energy conversion systems requires increased attention to receiver optical performance and system thermal efficiency for cost effective operation. Flat plate and low concentration ratio (2-3 X) evacuated tube collectors have large area receivers and thus place a premium on absorber surface cost as well as performance. Intermediate and high concentration ratio systems ( $>50 \mathrm{X}$ ) focus sunlight into a line or a point and may reflect light through the aperture of a cavity. A variety of such systems is illustrated in Figure 1-1. The importance of the optical properties of the receiver depends on the particular system design.

Numerous requirements are placed on absorber surfaces across the spectrum of solar thermal energy conversion systems, and no single material is appropriate for all applications. The adequacy of available absorber materials varies from application to application; the solar thermal energy conversion systems for which improved receiver performance, cost, or durability are important motivate an absorber surfaces R\&D effort.

For approximately 25 years, R\&D activities have addressed selective absorption where the receiver surface exhibits simultaneously a low reflectance (high absorptance) in the solar spectral region and a high reflectance (and thus low emittance) in the thermal infrared spectral range. Early work in this field, beginning in 1955, investigated a number of techniques for obtaining high solar absorptance and low thermal emittance at low temperatures $\left(200^{\circ} \mathrm{C}\right)$. However, the number of applications was limited and few concepts were commercialized. In the 1960 s the NASA space effort included extensive studies of the optical properties of surfaces with emphasis on controlling the temperature of spacecraft; however, the absorbing materials developed did not necessarily possess properties desirable for terrestrial use. During the last five years NSF/RANN, ERDA, and DOE support has led to the adaptation of black chrome for 


\section{Two Axis Tracking}

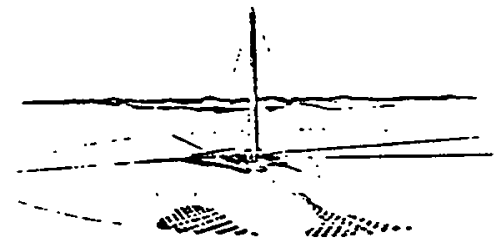

Point Focus Central Receiver

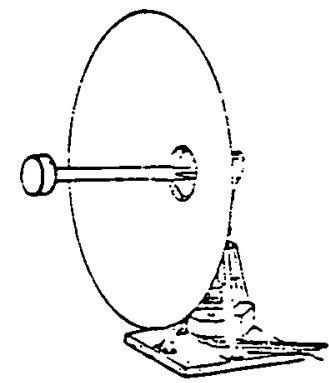

Point Focus Distributed Dish

\section{Single Axis Tracking}

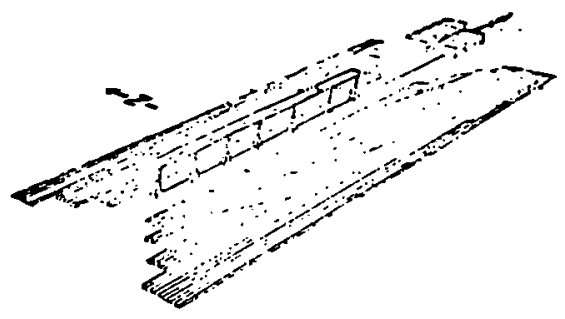

Linear Focus Central Receiver

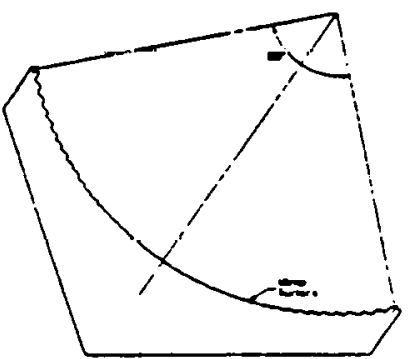

Fixed Mirror Concentrator Trough

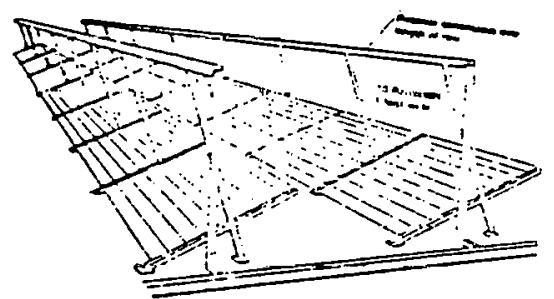

\section{SLATS ISegmented Linear} Array Thermal Systeml

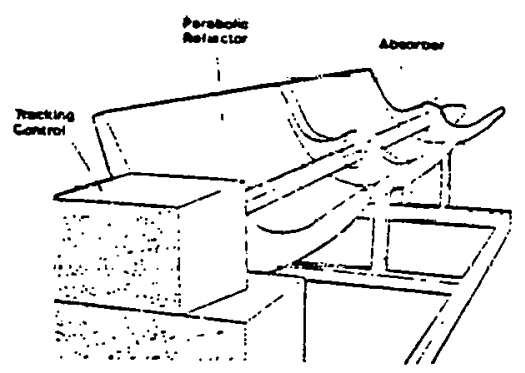

Parabolic Trough

\section{Non Tracking}

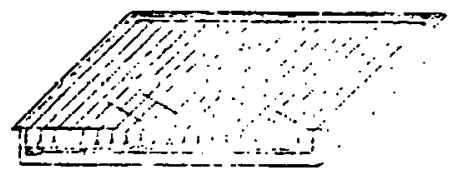

Flat Plate Collector with 3:1 Concentrator

Figure 1-1. Active Solar Thermal Energy Conversion Devices 
applications to $300^{\circ} \mathrm{C}$ and programs to develop higher-temperature-selective and nonselective absorber surfaces as well as more cost-effective and durable lowtemperature coatings. Studies of the basic properties of absorbers have also been initiated.

This document describes a National Program Plan for Absorber Surface R\&D. The benefits of improved absorber surfaces for generic applications are contrasted with the properties, and thus the suitability, of available absorber materials to derive the priority $R \& D$ elements of the program plan. Generic research issues (e.g., effects of morphology, manufacturing processing, research into fundamental mechanisms of coating degradation, and systems analysis) which are not logically restricted by solar application argue for a holistic approach to an Absorber Surfaces Program, and thus the planning effort spans technology boundaries (Solar Thermal Power, Agricultural and Industrial Process Heat, and Solar Hot Water Heating and Space Heating and Cooling). The program seeks to coordinate and improve communication between ongoing activities and to direct scientific and production expertise through a program that is balanced with respect to application (low/intermediate/high temperatures, vacuum/atmosphere, etc.) and function (basic/applied research, development, testing, measurements, etc.).

The background that supports the design of the plan appears in Section 2. The program plan, defined in Section 3, provides an effort which will satisfy identified system needs within the context of the objective, goals, and scope defined in this section. SERI's role is summarized explicitly in Section 4.

\subsection{OBJECTIVES}

The objective of a coordinated Absorber Surface Program is to assist the timely development of high performance, durable, and cost-effective solar absorbers needed by designers of solar thermal and solar thermal electric systems.

Four specific development goals have been defined to meet this objective:

- identify and develop improved cost-effective solar selective absorbers for passive, flat plate, and evacuated tube applications to $200^{\circ} \mathrm{C}$;

- establish the commercial viability of black chrome for concentrator applications to $400^{\circ} \mathrm{C}$ and identify an alternative absorber surface for these applications;

- develop a selective absorber and identity a backup for concentrator applications from $400^{\circ} \mathrm{C}$ to $700^{\circ} \mathrm{C}$; and

- investigate the optical and protective properties of absorber surfaces required for applications at temperatures above $700^{\circ} \mathrm{C}$. 


\subsection{SCOPE}

The Absorber Surfaces Program has been projected for five years with maximum involvement of industry in the development projects. Universities and nationa1 laboratories will be used primarily in research and support activities. The success of the program will be reviewed annually and measured against the identified goals.

\subsection{APPROACH}

The approach of the program will be to lower front-end risks by providing research funds to demonstrate technical feasibility of absorber surface concepts. Cost-sharing assistance in the developmental stage will provide further support. Commercial markets will be stimulated by identifying applications, certifying test procedures, and providing information. 


\section{SECTION 2.0}

\section{TECHNICAL ASSESSMENT}

\subsection{STATE-OF-THE-ART ABSORBER SURFACES}

The maximization of the absorption and thermal conversion of photons at a solar receiver surface is crucial for the development of cost effective solar applications. A large solar absorptance $\left(\alpha_{\mathrm{s}}\right)$ can be achieved by designing the receiver as a cavity, by relying on special absorbing properties of the receiver surface, or a combination of both. In all three cases, the thermal efficiency of the receiver, $\eta$, is the fraction of the incident energy absorbed minus the losses from radiation, conduction, and convection. Equation (1) [1] is a simplified relationship, however an exact calculation of the receiver efficiency requires detailed knowledge of the incident solar flux and the receiver temperature as a function of time and position on the receiver surface.

$$
\eta=a_{\mathrm{s}}-\frac{1}{\phi \overline{\tau X}}\left[\mathrm{~F}\left(\epsilon_{\mathrm{t}_{1}}, \epsilon_{\mathrm{t}_{2}}\right)\left(\mathrm{T}_{1}{ }^{4}-\mathrm{T}_{2}{ }^{4}\right)+\mathrm{Q}_{\text {conv }}+\mathrm{Q}_{\text {cond }}\right]
$$

where

$$
\begin{aligned}
\alpha_{\mathrm{s}}= & \text { Solar absorptance } \\
\epsilon_{\mathrm{t}_{1}}= & \text { Thermal enittance of absorber surface } \\
\epsilon_{\mathrm{t}_{2}}= & \text { Thermal emittance of environment surrounding } \\
& \text { absorber surface } \\
\mathrm{F}\left(\epsilon_{\mathrm{t}_{1}}, \epsilon_{\mathrm{t}_{2}}\right)= & \text { Function of } \epsilon_{\mathrm{t}_{1}} \text { and } \epsilon_{\mathrm{t}_{2}} \text { determined by } \\
& \text { receiver geometry and orientation } \\
\sigma= & \text { Stefan Boltzmann constant }\left(5.67 \times 10^{-8} \mathrm{Wm}^{-2}{ }^{\circ} \mathrm{K}^{-4}\right) \\
\tau= & \text { Transmittance through the system optics } \\
\phi= & \text { Insolation (direct for most concentrating systems) } \\
\mathrm{Q}_{\mathrm{conv}}= & \text { Convective heat loss per unit area } \\
\mathrm{Q}_{\mathrm{cond}}= & \text { Conductive heat loss per unit area } \\
\mathrm{T}_{1}= & \text { Surface temperature of the absorber surtace ( } \left.\mathrm{l}^{\prime}\right) \\
\mathrm{T}_{2}= & \text { Temperature of environment surrounding receiver }
\end{aligned}
$$


The concentration factor, $X$, is determined in equation (2).

$$
X=\frac{{ }_{C}}{{ }_{r}} E \rho
$$

where

$A_{c}=$ Effective aperture area of concentrator mirror or lens

$A_{r}=$ Reradiating area of external receiver

$\mathrm{E}=(1-\mathrm{e})$ where $\mathrm{e}$ is the fraction of energy lost due to mirror surface imperfections and sun tracking errors

$\rho=$ Specular reflectance of mirror surface within the maximum useful cone angle

For concentrating systems $\mathrm{F}\left(\epsilon_{\mathrm{t}_{1}}, \epsilon_{\mathrm{t}_{2}}\right)\left(\mathrm{T}_{1}^{4}-\mathrm{T}_{2}^{4}\right)$ reduces to $\epsilon_{\mathrm{t}_{1}}\left(\mathrm{~T}_{1}^{4}-\mathrm{T}_{2}{ }^{4}\right)$, or as it is more conventionally written $\epsilon \overline{\mathrm{T}}^{4}$ (assuming $\overline{\mathrm{T}}_{2} / \mathrm{T}_{1}<<\mathrm{i}$ ).

In general, as the system design operating temperature increases and/or the geometric concentration ratio decreases, the thermal radiative losses dominate as a result of $\mathrm{T}^{4}$ dependence and, as illustrated in Figure 2-1, system performance is improved by reducing the thermal emittance $\left(\epsilon_{t}\right)$ of the receiver. A receiver surface with high solar absorptance and low thermal emittance is described as a selective absorber surface, and since 1955 [2] a significant scientific effort has attempted to achieve the ideal step-function optical properties illustrated as the dashed line in Figure 2-2.

A single material with the appropriate properties is the preferred choice from a processing point of view; however, at present hafnium carbide (HfC) and rhenium oxide $\left(\mathrm{ReO}_{3}\right)$, both having relatively poor optical selectivity, are the best candidates in this category [3]. In practice, successful selective solar absorber materials utilize a combination of the physical mechanisms listed in Table 2-1.

The status of commercial and developmental absorber surfaces is summarized in Table 2-2. A literature survey has revealed more than 1,000 references to selective solar absorbers and, therefore, citations will be made to secondary (review) sources wherever possible. A good overview of selective absorber surfaces is found in references $[3-10]$.

\section{1 .1 Commercial Coat1ngo}

\subsubsection{Selective}

Black chrome (a granular film of (r metal and mixed chrome oxide particles) dominates the absorber surface market in both flat plate solar collectors and in concentrating collectors where the peak temperatures are below $300^{\circ} \mathrm{C}$. This electroplated coating has a solar absorptance of 0.95 and a thermal emittance at $100^{\circ} \mathrm{C}$ below 0.10 , when deposited on a rough nickel reflector layer. 


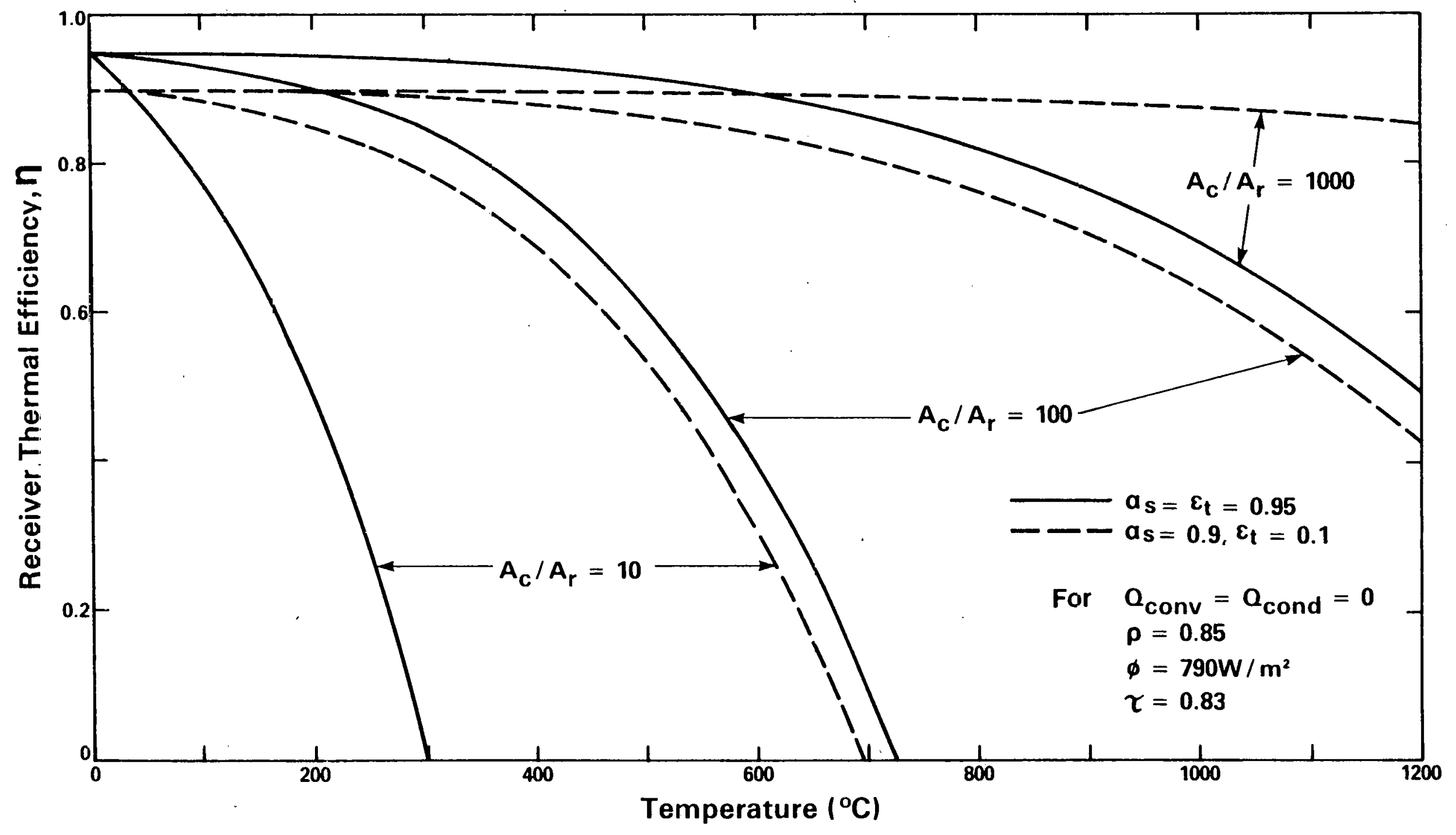

Figure 2-1 Receiver Thermal Efficiency 


\section{Optimum Spectral Reflectance of a Selective Absorber Surface}

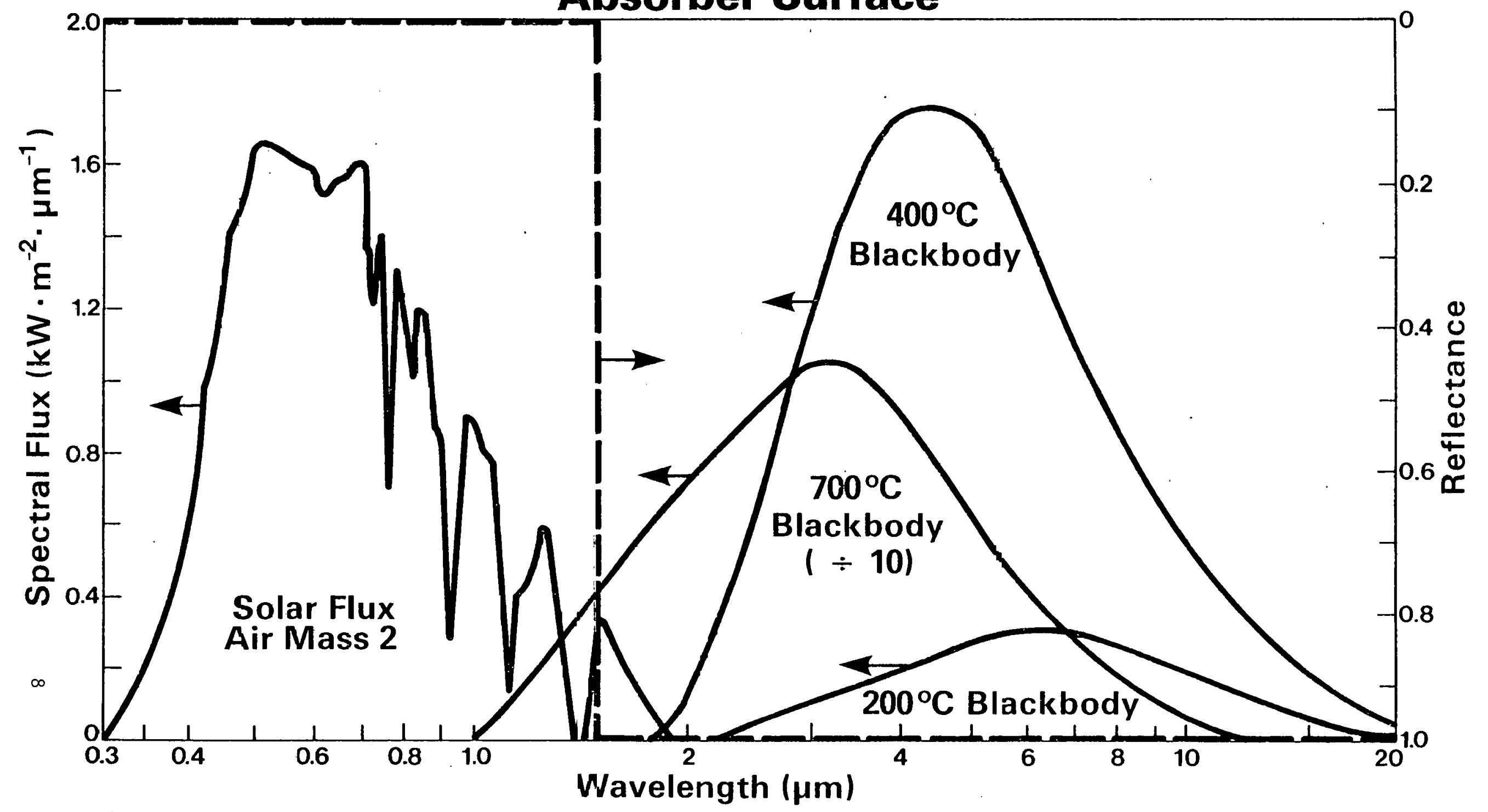

Note: The wavelength for the optimum reflectance step (dashed line) depends on the temperature of the radiating surface (19). 


\section{Generic Types of Selective Absorber Surfaces}

Single Material with Ideal Intrinsic Solar Absorptance/ IR Reflectance

Bilayer (IR reflector/solar absorber tandem)

Multilayer (interference)

Surface Topography (light trapping morphology with physical dimension approximately equal to the wavelength of the solar spectrum)

Small Particle Effects (Mie scattering, resonance and dielectric anolamies)

Table 2-1 


\begin{tabular}{|c|c|c|c|c|c|c|c|c|}
\hline $\begin{array}{l}\text { Material } \\
\text { Black Chrome }\end{array}$ & $\begin{array}{r}\text { Technique } \\
\text { electro-deposited }\end{array}$ & $\begin{array}{l}\text { Supplier(S)/ Developer(D) } \\
\text { Many }\end{array}$ & $\begin{array}{c}\text { Maturity } \\
5 \text { (lowT) } \\
4 \text { (highT) }\end{array}$ & $\begin{array}{c}a_{8} \\
0.94-0.96\end{array}$ & $\begin{array}{c}\varepsilon_{4}(T) \\
0.05-0.10 ; 100) \\
0.20-0.25 ; 300)\end{array}$ & $\begin{array}{c}\text { T Stability" } \\
\left.{ }_{300}^{\circ} \mathrm{C}\right)\end{array}$ & Issues & $\begin{array}{l}\text { Ref } \\
27\end{array}$ \\
\hline Pyromark & paint & Tempil & 5 & 0.95 & $0.85(500)$ & $<750$ & & 27 \\
\hline $\begin{array}{l}\text { S-31 } \\
\text { Nonselective }\end{array}$ & paint & Rockwell International & 5 & $0.8-0.85$ & $0.8-0.85$ & $>550$ & $\begin{array}{c}\text { adhesion, } \\
\text { curing } \\
\text { process }\end{array}$ & 27 \\
\hline $\begin{array}{l}\text { SOLARTEX } \\
\text { SOLAROX } \\
\text { (Proprietary: }\end{array}$ & $\begin{array}{l}\text { Electro-Deposited } \\
. .\end{array}$ & Dornier (W. Germany) & $\begin{array}{l}\mathbf{5} \\
\mathbf{5}\end{array}$ & $\begin{array}{l}0.93-0.96 \\
0.92\end{array}$ & $\begin{array}{l}0.14-0.18(310) \\
0.20\end{array}$ & $\begin{array}{l}700 \\
200\end{array}$ & & $\begin{array}{l}\text { Product } \\
\text { Literature }\end{array}$ \\
\hline Black Epoxy & Paint & Amicon Corp. & 5 & NA & NA & NA & & $"$ \\
\hline $436 \cdot 3 \cdot 8$ & ". & Bostik (U.S.M. Corp.) & 5 & 0.90 & 0.92 & NA & & $"$ \\
\hline Enersorb & $\ddot{\prime \prime}$ & Desoto & 5 & 0.96 & 0.92 & NA & & 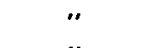 \\
\hline$\pi 729$ & $"$ & C. H. Hare & 5 & 0.96 & $0.90-0.92$ & NA & & $"$ \\
\hline R-412 & 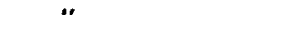 & Rusto-leum Co. & 5 & 0.95 & 0.87 & NA & & $"$ \\
\hline 5779 & $"$ & & 5 & 0.95 & 0.90 & NA & & $"$ \\
\hline $\begin{array}{l}\text { Nextel } \\
\text { (nonselective) }\end{array}$ & $\ddot{*}$ & $3-M$ & 5 & $0.97-0.98$ & $>0.90$ & 150 & & $\begin{array}{l}\text { product } \\
\text { bulletin } 206\end{array}$ \\
\hline $\begin{array}{l}\text { NOVAMET } 150 \\
\text { (proprietary) }\end{array}$ & 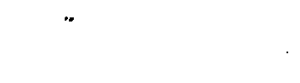 & Ergenics & 5 & 0.96 & 0.84 & $\begin{array}{l}800 \\
(1 \mathrm{hr})\end{array}$ & & 30 \\
\hline MAXORB & (proprietary) & Ergenics & 5 & $0.97( \pm .01)$ & $0.10( \pm .1 \mathrm{IB})$ & $\begin{aligned} & 150(20 \mathrm{wks}) \\
< & 400(1 \mathrm{hr})\end{aligned}$ & & 30 \\
\hline $\begin{array}{l}\text { Tabor black } \\
\text { (NiS / ZnS) }\end{array}$ & $\begin{array}{l}\text { electrodeposited } \\
\& \text { overcoat }\end{array}$ & Miromit & 5 & 0.91 & 0.14 & - & & \\
\hline proprietary & Vacuum deposited & GE & 5 & - & - & - & & 12 \\
\hline $\begin{array}{l}A l_{2} O, M O-A I_{:} O \\
(A M A)\end{array}$ & $\begin{array}{l}\text { sputtering } \\
\text { evaporztion }\end{array}$ & Honeywell & 4 & $0.85-0.95$ & $\begin{array}{l}0.34\{10 C\} \\
0.11-0.4\end{array}$ & $>550$ & & 9 \\
\hline $\begin{array}{l}\text { Multilayer } \\
\text { (propriatary: }\end{array}$ & proprietary & OCLI & 4 & 0.95 & $0.05\{10 \mathrm{C}\}$ & $>\mathbf{3 0 0}$ & & 13 \\
\hline $\mathrm{NiS} / \mathrm{ZnS}$ & $\begin{array}{l}2 \text { Layer Elec- } \\
\text { troplated }\end{array}$ & Many & 3 & 0.96 & 0.07 & $<250$ & $\begin{array}{l}\text { moisture } \\
\text { sensitive }\end{array}$ & 9 \\
\hline $\begin{array}{l}\text { Proprietary } \\
\text { Inorganic }\end{array}$ & paint & Martin Marietta & 3 & $0.9-0.95$ & $0.9-0.95$ & $>550$ & $\begin{array}{l}\text { adhesion. } \\
\text { curing }\end{array}$ & 27 \\
\hline $\begin{array}{l}\text { Selective } \\
\text { paint }\end{array}$ & dip coated & Honeywell & 3 & 0.92 & 0.131100 & $>150$ & & 8 \\
\hline $\begin{array}{l}\mathrm{Si} / \mathrm{Ag} \\
\text { bilayer w/AR }\end{array}$ & CVD & U. of Arizona & 3 & 0.80 & $\begin{array}{l}0.071500 \\
0.05(100\end{array}$ & 500 (vacuum) & & 8 \\
\hline $\mathrm{CuO} / \mathrm{Ag} / \mathrm{Ri}_{2} \mathrm{O}_{3}$ & $\begin{array}{l}\text { fired o-gano- } \\
\text { metallic paint }\end{array}$ & Engelhard & 3 & 0.9 & 0.1 & $<400$ & & 8 \\
\hline $\mathrm{CuO} / \mathrm{Au}$ & $\begin{array}{l}\text { fired o: yano- } \\
\text { metallic paint }\end{array}$ & Engelhard & 3 & 0.8 & 0.06 & $>600$ & & 8 \\
\hline $\begin{array}{l}\text { Silicone \& } \\
\text { silicate }\end{array}$ & paint & EXXON & 3 & 0.98 & 0.9 & $>700$ & & 8 \\
\hline $\begin{array}{l}\mathrm{Au} / \mathrm{Al}_{2} \mathrm{O}_{2} \\
\text { (cermet) }\end{array}$ & sputtering & U. of Sydney & 2 & 0.95 & 0.025120 & $<300$ & & 31 \\
\hline $\begin{array}{l}\mathrm{Cu} / \mathrm{Al}_{2} \mathrm{O}_{3} \\
\text { (cermet) }\end{array}$ & sputter ng & U. of Sydney & 2 & 0.91 & 0.045120 & $<200$ & & 31 \\
\hline $\begin{array}{r}5 \mathrm{nO}_{2}: \mathrm{F} / \text { Black } \\
\text { Enamel }\end{array}$ & Spray & $\begin{array}{l}\text { University of Delft } \\
\text { (The Netherlands) }\end{array}$ & 2 & 0.92 & 0.15 & 200 & $\begin{array}{l}\text { Very } \\
\text { Rugged }\end{array}$ & \\
\hline
\end{tabular}




\begin{tabular}{|c|c|c|}
\hline $\begin{array}{l}\text { Sten } \\
\text { stainless steel } \\
\text { dendrites }\end{array}$ & $\begin{array}{l}\text { sputtering } \\
\text { chemical con- } \\
\text { version }\end{array}$ & IBM \\
\hline Gold smokes & gas evaporation & Many \\
\hline \multirow[t]{3}{*}{ Germanium } & gas evaporation & Many \\
\hline & $\begin{array}{l}\text { paint (silicone } \\
\text { binder) }\end{array}$ & Many \\
\hline & etched & Penn State U \\
\hline $\begin{array}{l}\text { Au / Mgo } \\
\text { cermet }\end{array}$ & If sputtering & MIT -incoln L \\
\hline $\begin{array}{l}\mathrm{Cr} / \mathrm{Cr}_{2} \mathrm{O}, \\
\text { cermet }\end{array}$ & If sputtering & MIT_incoln L \\
\hline $\begin{array}{l}\text { SiO-Cr-SiO } \\
\text { multilayer }\end{array}$ & vacuum evaporation & \\
\hline $\begin{array}{l}\mathrm{Ni} / \mathrm{Al}_{2} \mathrm{O}_{3} \\
\text { cermet }\end{array}$ & evaporation & Cornell U. \\
\hline $\begin{array}{l}\mathrm{Pt} / \mathrm{Al}_{2} \mathrm{O}, \\
\text { cermet }\end{array}$ & vacuum evap & Cornell U. \\
\hline$a-\mathbf{S i}$ & plastra discharge & ANL! BNL \\
\hline $\begin{array}{l}\mathrm{Si} / \mathrm{CaF}_{2} \\
\mathrm{Ge} / \mathrm{CaF}_{2} \\
\text { cermets }\end{array}$ & sputtering & RCA \\
\hline $\begin{array}{l}\mathrm{Al}_{2} \mathrm{O}_{3} / \\
\mathrm{ZrC} \mathrm{C}_{x} \mathrm{~N}_{\mathbf{y}} / \mathrm{Ag}\end{array}$ & $\begin{array}{l}\text { reactive } \\
\text { sputtering }\end{array}$ & $\begin{array}{l}\text { Albany, Or } \\
\text { Bureau of Min }\end{array}$ \\
\hline Aluminum & $\begin{array}{l}\text { anodized (organic } \\
\text { dye) } \\
\text { anodized (KMnO. } \\
\text { dye) }\end{array}$ & \\
\hline \multirow[t]{2}{*}{ PbS } & vacuum deposited & \\
\hline & $\begin{array}{l}\text { paint Isilicone } \\
\text { binder) }\end{array}$ & \\
\hline $\mathrm{Cu}_{2} \mathrm{~S}$ & chemical conversion & \\
\hline$w C+c_{o}$ & plasmra spray & \\
\hline $\mathrm{Cr}_{2} \mathrm{O}_{3}+\mathrm{Co}_{0}$ & plasma spray & \\
\hline $\mathrm{Co}, \mathrm{O}$ & electroplated & \\
\hline $\begin{array}{l}304 \text { stainless } \\
\text { steel }\end{array}$ & $\begin{array}{l}\text { chemical conversion } \\
\text { thermal oxide }\left(760^{\circ} \mathrm{C}\right)\end{array}$ & \\
\hline $\begin{array}{l}\text { Inconel } \\
\text { and Incoloy }\end{array}$ & thermal oxide $11000^{\circ} \mathrm{C}$ & \\
\hline Steel $\left(F_{\theta}, O_{4}\right)$ & chemical conversion & \\
\hline
\end{tabular}

\begin{tabular}{|c|c|c|c|c|}
\hline 2 & 0.95 & - & $>550$ & $\begin{array}{l}\text { angle of } \\
\text { incidence }\end{array}$ \\
\hline 1 & 0.99 & $0.1(10 w T)$ & 100 & \\
\hline 1 & 0.91 & $\begin{array}{l}0.2(160), \\
0.5(250)\end{array}$ & & \\
\hline 1 & 0.91 & $0.8(200)$ & & \\
\hline 1 & & & $<400$ & \\
\hline 1 & 0.93 & 0.1 & $<300$ & \\
\hline 1 & 0.92 & 0.08 & $<400$ & \\
\hline 1 & 0.88 & $0.1($ lowT $)$ & $<450$ & \\
\hline 1 & 0.94 & $\begin{array}{l}0.161100 \\
0.35(500)\end{array}$ & 500 & \\
\hline 1 & 0.94 & $<0.3(500)$ & 600 & \\
\hline 1 & $\begin{array}{l}>0.9 \\
\quad \text { (calc.) }\end{array}$ & - & $>500$ & \\
\hline 1 & 0.7 & $<0.1$ & & \\
\hline 1 & 0.91 & $<0.05$ & $\begin{array}{l}\text { 175(air) } \\
\text { 700(vacuum) }\end{array}$ & \\
\hline 1 & 0.96 & 0.9813501 & $<350$ & \\
\hline 1 & 0.80 & $0.35(<100)$ & & \\
\hline 1 & 0.98 & $\begin{array}{l}0.05(100) \\
0.2(240) \\
0.3(300)\end{array}$ & 300 & $\begin{array}{l}\text { UV \& } \mathrm{O}_{2} \\
\text { stability }\end{array}$ \\
\hline 1 & 0.94 & $<0.8(200)$ & & $\begin{array}{l}\text { binder } \\
\text { thickness }\end{array}$ \\
\hline 1 & 0.79 & $0.2(200)$ & - & \\
\hline 1 & 0.95 & $\begin{array}{l}0.28(200) \text {, } \\
0.4(600)\end{array}$ & $>800$ & \\
\hline 1 & $0.9(800)$ & $0.5(800)$ & $>800$ & \\
\hline 1 & 0.9 & $0.3(140)$ & $>1000$ & \\
\hline 1 & 0.91 & - & - & \\
\hline 1 & 0.82 & $\begin{array}{l}0.15(100), \\
0.2(300)\end{array}$ & - & \\
\hline 1 & $0.85-0.90$ & - & 1000 & \\
\hline 1 & 0.90 & $\begin{array}{l}0.07(90) \\
0.35(200)\end{array}$ & - & \\
\hline
\end{tabular}

- Maturity: development status of absorber surfaces, 5 commercial, 3 development, 1 research.

- Temperature stability for most absorber surfaces is poorly defined and depends critically on exposure environment, conditions of test and survival criteria.

Properties of Selected Solar Absorber Surfaces

Table 2-2 
At $300^{\circ} \mathrm{C}$ the thermal emittance is approximately 0.25 . For applications above $300^{\circ} \mathrm{C}$ black chrome has shown an irreversible degradation in solar absorptance; however, recent Sandia-Albuquerque research has progressed toward stabilizing black chrome for applications to $400^{\circ} \mathrm{C}$ by controlling the $\mathrm{Cr}^{+3}$ bath concentration during electroplating [11]. Black chrome produced by reactive sputtering or physical vapor deposition (PVD) onto metallized glass tubes is used by manufacturers of evacuated tube solar collectors [12].

Electroplated black nickel (NiS) coatings have been studied extensively, and some commercial coatings have been applied to flat plate collectors. Black nickel is not useful above $250^{\circ} \mathrm{C}$ and does not resist humidity well, thus requiring a protective overcoat. A polymer overcoat thick enough to act as a moisture barrier also contributes to the thermal emittance of the black nickel absorber surface, thus reducing the optical efficiency for some applications.

The alumina-molybdenum-alumina (AMA) absorber coating on a thin molybdenum layer deposited on stainless steel is a sophisticated evaporated or sputtered multilayer interference coating developed by Honeywell. The coating appears to be stable to $500^{\circ} \mathrm{C}$, with room temperature solar absorptance to 0.96 and thermal emittance of approximately 0.10. High-temperature degradation results from the diffusion of oxygen and carbon from the stainless steel. A diffusion barrier, such as a thermally grown chrome oxide layer between the nolybdenum and the stainless steel, may extend the temperature range to $600^{\circ} \mathrm{C}$. Recent work on multilayers has demonstrated optical properties of $\alpha_{s}=0.95$ and $\epsilon_{t}=$ 0.05 for applications to $100^{\circ} \mathrm{C}[13]$.

\subsubsection{Non-Selective}

A large number of black paints, most of which are not optimum for solar applications, are available from commercial sources. Pyromark paint [14] has been extensively tested for thermal and photothermal degradation in connection with the Barstow, California $10 \mathrm{MW}_{\mathrm{e}}$ central receiver pilot plant. When properly applied the paint is adherent and has a stable solar absorptance greater than 0.95 for peak temperatures and solar fluxes in excess of $800^{\circ} \mathrm{C}$ and $1 \mathrm{MW} / \mathrm{m}^{2}$, respectively.

Black paints for applications above $500^{\circ} \mathrm{C}$ have been developed by McDonnel1Douglas and Martin-Marietta; however, complicated processing and adhesion problems with these paints have focused attention on Pyromark.

Nonselective plasma spray coatings have been investigated for use above $500^{\circ} \mathrm{C}$. The range of reported solar absorptance values [9, 15, 16] is not outstanding and, to date, applications have not required the potential high-temperature durability of such coatings.

\subsubsection{Developmenta1 Absorber Surfaces}

The DOE R\&D effort in absorber surfaces is funded by Energy Technology (ET), Conservation and Solar Applications (CS), and the Basic Energy Science Division of the Office of Energy Research (OER/BES). 


\subsubsection{Energy Technology}

The Absorber Materials Program supported by the Advanced Solar Thermal Technology Program is comprised of seven contracts with research on six topics: (1) the development of high-temperature nonselective black paints (Exxon); (2) the development of semiconductor/metal multilayer selective absorber films deposited by chemical vapor techniques (University of Arizona); (3) the development of selective coatings using metallo-organic paint technology (Engelhard Industries); (4) the development of metal/insulator and semiconductor/insulator composite absorbers (Cornell University and RCA Laboratories); (5) the investigation of the mechanisms of absorptance and emittance and the degradation of the optical properties of absorber coatings (Cornell University and University of Houston); and (6) a nalytical support for chemical and atomic analysis and the investigation of sputtering techniques for producing selective absorber coatings (University of Minnesota). Four absorber coatings with excellent optical properties have been demonstrated by the program: Exxon paints $\left[\alpha_{\mathrm{s}} \geq 0.98\right]$, Engelhard metallo-organic films of the $\mathrm{Ag} / \mathrm{CuO} / \mathrm{Rh}_{2} \mathrm{O}_{3}$ type $\left[\alpha_{s}=0.91, \epsilon_{t}\left(300^{\circ} \mathrm{C}\right)=0.1-0.2\right]$ and two Cornell University cermets, $\mathrm{Ni} / \mathrm{Al}_{2} \mathrm{O}_{3}\left[\boldsymbol{\alpha}_{\mathrm{s}}=0.94, \epsilon_{\mathrm{t}}\left(100^{\circ} \mathrm{C}\right)=0.16\right]$ and $\mathrm{Pt} / \mathrm{Al}_{2} \mathrm{O}_{3}\left[\boldsymbol{\alpha}_{\mathrm{s}} \geq 0.9, \epsilon_{\mathrm{t}} \leq 0.3\right.$ $\left.\left(600^{\circ} \mathrm{C}\right)\right\}$.

In addition, the University of Houston modelling activity may lead to a better understanding of the degradation of black chrome.

Two contracts were completed during FY77. The University of Arizona concluded that the high temperature thermal oxides on the surface of many construction alloys have a stable solar absorptance between 0.8 and 0.9 . A study by Argonne National Laboratory concluded that amorphous silicon can be prevented from crystallizing at temperatures above $500^{\circ} \mathrm{C}$ and that a solar absorptance of 0.91 can be obtained with a $1 \mu \mathrm{m}$ thick $\mathrm{film}$, if the reflection loss at the semiconductor/air interface can be eliminated.

\section{2,1,2,2 Conservation and Solar Applications}

Research and development activities for improved absorber surfaces for lowtemperature and passive applications are being funded through SHAC R\&D and were initiated through PRDA 3 and. RFP 22 procurements in FY//. 'l'hese contracts will explore electroplated coatings (Berry Solar Products), electrodeposition of paint (DeSoto, Inc.), selective paints (Honeywe1l), black germanium (Penn State), reactively sputtered coatings (TELIC), and coating stability (Owens-Illinois). Under earlier contracts from NSF, Honeywell has demonstrated selective paints with solar absorptance greater than 0.9 and thermal emittance of approximately 0.15 using an iron-manganese-copper oxide pigment in either silicone or aliphatic urethane binders [17].

\subsubsection{Basic Energy Sciences}

Materials research for photothermal conversion is also funded through Basic Energy Sciences (BES). In FY77, this work included optical properties measurements (Ames, Argonne, and Oak Ridge National Laboratories); amorphous 
materials (Argonne, Lawrence Berkeley, and Brookhaven National Laboratories); sputtcred coatings (Battelle Pacific Northwest Laboratory). The program has been expanded significantly in FY78 and includes a contract with the University of Arizona to study the preparation of high-absorptance amorphous semiconductor films by CVD and work at Brookhaven National Laboratories to investigate amorphous materials.

\subsubsection{Other (Non-DOE)}

Non-DOE sponsored activities have included a wide range of studies. The chemical modification of substrate surfaces, such as the sodium dichromate [Ebanol] treatment of copper, steel, and stainless steel and oxidation or sulfidizaton of construction materials has been explored with some success. Textural and/or selective microstructural scattering effects such as dendritic

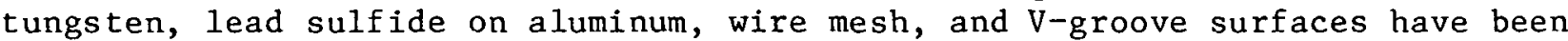
investigated. $R \& D$ has also been done on mie scattering films such as metal smokes, metal-insulator, or semiconductor-insulator combinations produced by cosputtering or coevaporation. Gold/insulator cermets have demonstrated optical properties $\left(a_{s}>0.9, \epsilon_{t}\left(100^{\circ} \mathrm{C}\right)<0.05\right)$ with potential applications in evacuated tube or inert gas collector geometries.

A large number of concepts for selective solar absorbers have been demonstrated both within and outside DOE programs. Obtaining the proper optical properties--although not trivial--is only the first step toward producing a viable commercial absorber surface. The issues of concern to absorber surface developers and users are listed in Table 2-3. Limitations in the reproducibility of the production process, magnitude of the optical acceptance angle, durability, and cost have motivated continued exploration of new concepts; however, as the field matures the benefits derived from new concepts must be evaluated with respect to evolutionary research to address the limitations of established absorber systems. The program management of the Absorber surfaces rrogram will perform this evaluation and balance the program according $\perp$.

\subsection{APPLICATIONS}

The receiver surface is common to all solar thermal systems, from passive structural elements to point focus collectors. The systems under consideration and the range of operating temperatures and concentration ratios are summarized in Table 2-4. For many applications the design operating temperature $\left(500^{\circ} \mathrm{C}\right)$ is limited by other materials constraints than absorber material availability (such as working fluid/heat transfer system compatibility.) Should these constraints be removed and operating temperatures increase renewed interest in high temperature selective absorbers may be expected. It is important that potentially viable systems not fail in commercialization because of the lack of a suitable absorber surface. It is also important that systems that are not potentially viable not be used to justify absorber surface $R \& D$. In addition, absorber surface development cannot be justified for systems that do not benefit significantly from improved receiver optical properties. 


\section{Issues of Concern for Absorber Surfaces}

- Operating Efficiency High $a_{s}(T)$

Low $\varepsilon_{t}(T)$

Angle of incidence effects High thermal conductivity

- Operating Life and Degradation Mechanisms Temperature stability (maximum operating temperature, gradient, transients [shock], and cycling [fatigue])

Effects of solar photon flux (UV) Impact and abrasion resistance (dust and hail) Effect of adherent dust on optical properties Chemical stability (atmospheric, working fluid and system contamination, rain, humidity) Vacuum stability

- Repairability

- Cost/unit area

- Materials resource limitation or vulnerability

- Geometrical constraints in application of coating

- Shaping or forming after coating

- Limitations on substrate candidates

Table 2-3 


\section{Solar Thermal Systems*}

\section{System}

Passive

Flat Plate

Evacuated Tube (CPC. V troughs)

Linear Fresnel and Cylindrical Trough

Linear Parabolic \& Segmented Linear

Array Tracking System (SLATS)

Two Axis Tracking Fresnel

Spherical Reflector Tracking Absorber

Two Axis Tracking Parabolic Dish

Central Receivers - Barstow 10 MWe

Steam Cycle (Ext. Rec.) 100 MWo

Adv. Molt. Salt \& Metal (Ext. Rec.)

Adv. Open \& Closed Adv. Brayton Cycles (cavity receiver)

\section{$\left.T,{ }^{\circ} \mathrm{C}\right)$}

$25-80$

$40-180$

$100-200$

$150-250$

$200-350$

$200-350$

300-500

$500-1100$

500

500

600

$1000 \cdot 1400$
$A_{c} / A_{r}$

1

1

$1.5-3$

$6 \cdot 10$

20-70

50- 100

$100-200$

1000

400

1200

$1800-2500$

$2500-4000$
$\beta=\frac{\sigma\left(T_{1}^{4}-T_{2}^{4}\right)}{\phi T A_{c} / A_{r}}$

0 -.7 $(\rho=1.0)$

$.13-3.7(\rho=1.0)$

.5-3.3

.3-1.3

$.07-.77$

$.05-.3$

$.06-.4$

$<.04-3.5$

.09

.03

$.03-.04$

*Parameters defined in equation 1 Assumes $\mathrm{T}=.83, \mathrm{E}=1.0, \rho=.85, \phi=790 \mathrm{~W} / \mathrm{m}^{2}, \mathrm{~T}_{2}=27^{\circ} \mathrm{C}$

Table 2-4 
The identification of viable systems involves a complex iterative process. The marketplace is the ultimate test of all systems; however, R\&D support programs must prejudge this process and err on the side of protecting the development process where budgets allow. The overall system cost-effectiveness is the factor that will determine market acceptance, and the cost/performance of the receiver system can be judged only as part of the total system. The Absorber Surfaces Program will anticipate that specific systems will be developed until analyses and experiments indicate that the concept is not viable, as a result of factors other than the optical properties of the receiver.

\subsection{BENEFIT ANALYSIS}

Whether funds should be invested in the development of absorber surfaces for a particular application and, if so, the type of coating required, can be determined only after critical analysis. When $R \& D$ funds are limited, such analysis must include the appropriate distribution of funds among competing component improvements. $R \& D$ investments leading to a potentially larger decrease in the cost of delivered energy should be funded first; however, since there is a critical minimum level of funding for maintaining expertise in areas of lower priority, these areas must be funded but at a reduced level in proportion to potential impact. If all the $R \& D$ areas in solar thermal power, for instance, are independently and accurately assessed (heat engines, heat transfer fluids, receiver heat transfer, reflector materials, and absorber materials), budgets can be assigned rationally on the basis of relative impact coupled with fiscal constraints. In addition, these same R\&D plans provide a powerful tool in subsequent budget cycles to relieve some fiscal constraints.

There are three elements in the benefit analysis of absorber surfaces: optical performance of the surface, the cost of producing the desired properties, and the durability or lifecycle cost of the surface. The relative importance of the three parameters for a specific application depends on the system design, including the operating temperature, the geometric concentration ratio, and the receiver geometry. For low concentration ratio systems the cost of the absorber surface is important; as the concentration ratio increases, however, the breakeven cost of improving receiver optical properties based on the reduction of expensive mirror or lens area may be as high as several thousand dollars per square meter [18], assuming suitable durability. For high-temperature cavity applications, little or no concern for the optical properties of the receiver surface may be justified; however, the mechanical (material) durability of the surface as a barrier to cheminal or physical degradation of the receiver structure may be of considerable interest.

Each of the three parameters will be explored in some depth in the following paragraphs, and the section will conclude with a discussion of the benefit of current absorber surface $R \& D$ based on expected future value. 


\subsubsection{Optical Performance Analysis}

The direct optical benefit of a selective solar absorber increases with increasing receiver temperature and decreasing solar concentration ratio. The parameter $\boldsymbol{\beta}$, introduced in Table $2-4$, is a measure of this sensitivity of receiver efficiency to the emittance of the absorber surface.

If conduction and convection losses are neglected, equation 1 (page 5 ) can be re-expressed as

$$
\eta=\alpha_{\mathrm{s}}-\beta \epsilon_{t} \quad\left[\beta \equiv \frac{\sigma\left(\mathrm{T}_{1}^{4}-\mathrm{T}_{2}{ }^{4}\right)}{\phi \tau \rho \mathrm{E} \mathrm{A}_{\mathrm{c}} / \mathrm{A}_{\mathrm{r}}}\right]
$$

and it is clear that $\beta \epsilon_{t}$ must be less than $\alpha_{s}$ for the operating temperature of a system to be attained.

To identify legitimate development goals, a detailed benefit analysis has been started at JPL. In addition, Sandia-Albuquerque [19], Sandia-Livermore [20], and several central receiver contractors have also begun systems analysis studies to assess the benefit of improved receiver optical properties on specific system designs.

The measured effect of a selective absorber for flat plate systems has been addressed by NASA-Lewis [21,22]. These measurements, which are corroborated by Spitz [23], indicate that by replacing a nonselective with a selective absorber, the absolute improvement in receiver efficiency $(\Delta \eta)$ is 0.1 to 0.15 . The relative improvement in receiver performance $(\Delta \eta / \eta)$ is dependent on the operating conditions and the performance of other receiver components (e.g., transmission of the glazing) and can easily exceed $100 \%$.

Measured performance improvements for parabolic troughs with black chrome in place of a nonselective absorber indicate absolute improvements in receiver efficiency $\Delta \eta \approx 0.20$ at $250^{\circ} \mathrm{C}$ to $300^{\circ} \mathrm{C}$ corresponding to a $\Delta \eta / \eta$ of $150 \%[24]$,

Two recent studies $[1,20]$ have explored in greater detail than previous work the tradeotfs for generic systems. 'l'hese studies have calculated the benefit of receiver efficiency improvement, $\xi$, defined as

$$
\begin{aligned}
& \xi=\eta_{\mathrm{s}}-\eta_{\mathrm{r}} ; \quad \eta_{\mathrm{r}} \geq 0 \\
& \xi=\eta_{\mathrm{s}} ; \quad \eta_{\mathrm{r} .}<0
\end{aligned}
$$

for a receiver with a specific eelective abcorbcr surfacc $\left(\eta_{S}\right)$ comparcd to $a$ receiver with a specific nonselective absorber $\left(\eta_{r}\right)$. Isobenefit contours in the space of receiver temperature versus incident flux on the receiver are plotted in Figure 2-3, and the overlap of receiver operating conditions with regions of high benefit is illustrated. These analyses provide a necessary 


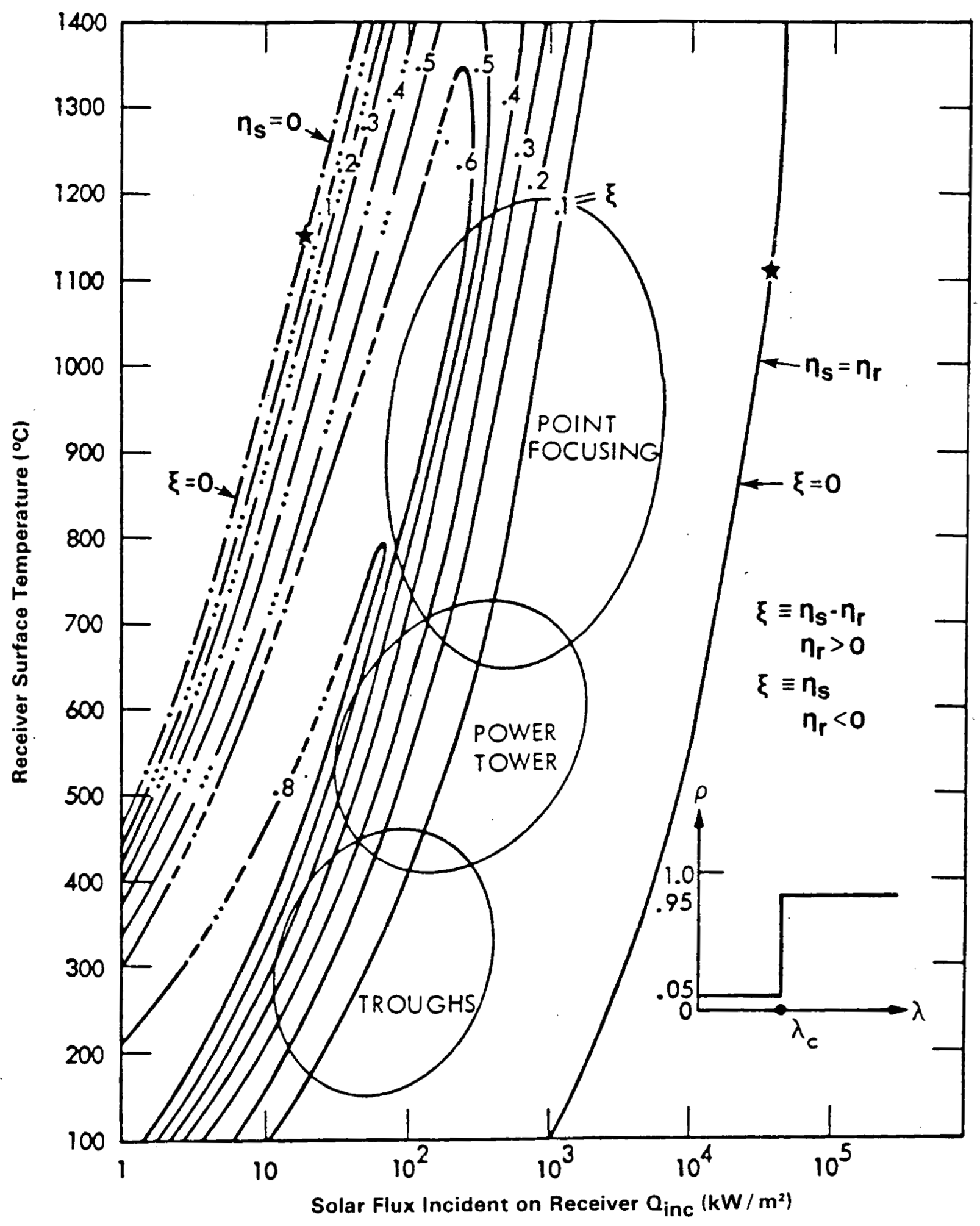

Figure 2-3 Isobenefit Contours for an Ideal Step Change Absorber Surface Reflectance [1] 
but not a sufficient condition for the development of an absorber surface for a generic application. Detailed analysis of the overlap region for specific systems is required to determine specific benefits.

A detailed JPL analysis on specific systems was done to determine the benefit of optical selectivity. This analysis was a function of:

- type of concentrator

* linear (parabolic trough)

$*$ point (central and distributed receiver)

- type of receiver

* external

* cavity

- geometric concentration ratio

- absorber temperature

The simplifying assumptions used to perform these analyses are important, and the reader should refer to [25,26] for details. Characteristics of the selective absorber surfaces were assumed to be ideal; that is, they possess a perfect step change reflectance with a low value $(-0)$ below and a high value $(\sim 1.0)$ above the cutoff wavelength.

For cavity central receivers at temperatures greater than $550^{\circ} \mathrm{C}$ (Figure 2-4), the receiver performance improvements projected for selective and high absorptance nonselective coatings compared to a degraded nonselective surface ( $\boldsymbol{\alpha}_{s}=$ $0.8)$ are sma11 $(\Delta \eta=0.03-0.08 ; \Delta \eta / \eta=4-10 \%)$. For externally irradiated central receivers at $550^{\circ} \mathrm{C}$, there is an incentive for improved absorptance $(\Delta \eta=0.12-0.15 ; \Delta \eta / \eta=15-20 \%)$ but essentially no additional advantage for selectivity at concentration ratios greater than 700 (.Figure 2-5).

For lower concentration ratios (200-400X) typical of the first $10 \mathrm{MW}_{\mathrm{e}}$ central receiver pilot plant, appreciable benefits can be achieved by using a good selective coating $(\Delta \eta=0.10-0.15, \Delta \eta / \eta=15-20 \%)$. In this case, $R \& D$ and design changes to improve the concentration ratio or cost effectiveness of cavities compete directly with the development of an improved absorber surface.

For distributed collectors there appears to be only marginal benefit in using either a good nonselective or a selective coating in cavity receiver designs for parabolic dish collectors (Figure 2-6). This appears to be true even at temperatures as high as $1100^{\circ} \mathrm{C}(\Delta \eta \approx 0.05, \Delta \eta / \eta \approx 5 \%)$. The parabolic trough systems that operate at much lower concentration ratios can be improved significantly with the use of selective coatings (Figure 2-7), as the previously discussed measurements [24] have verified. It will also be essential for higher temperature troughs to have either a cavity or a good selective absorber surtace. 


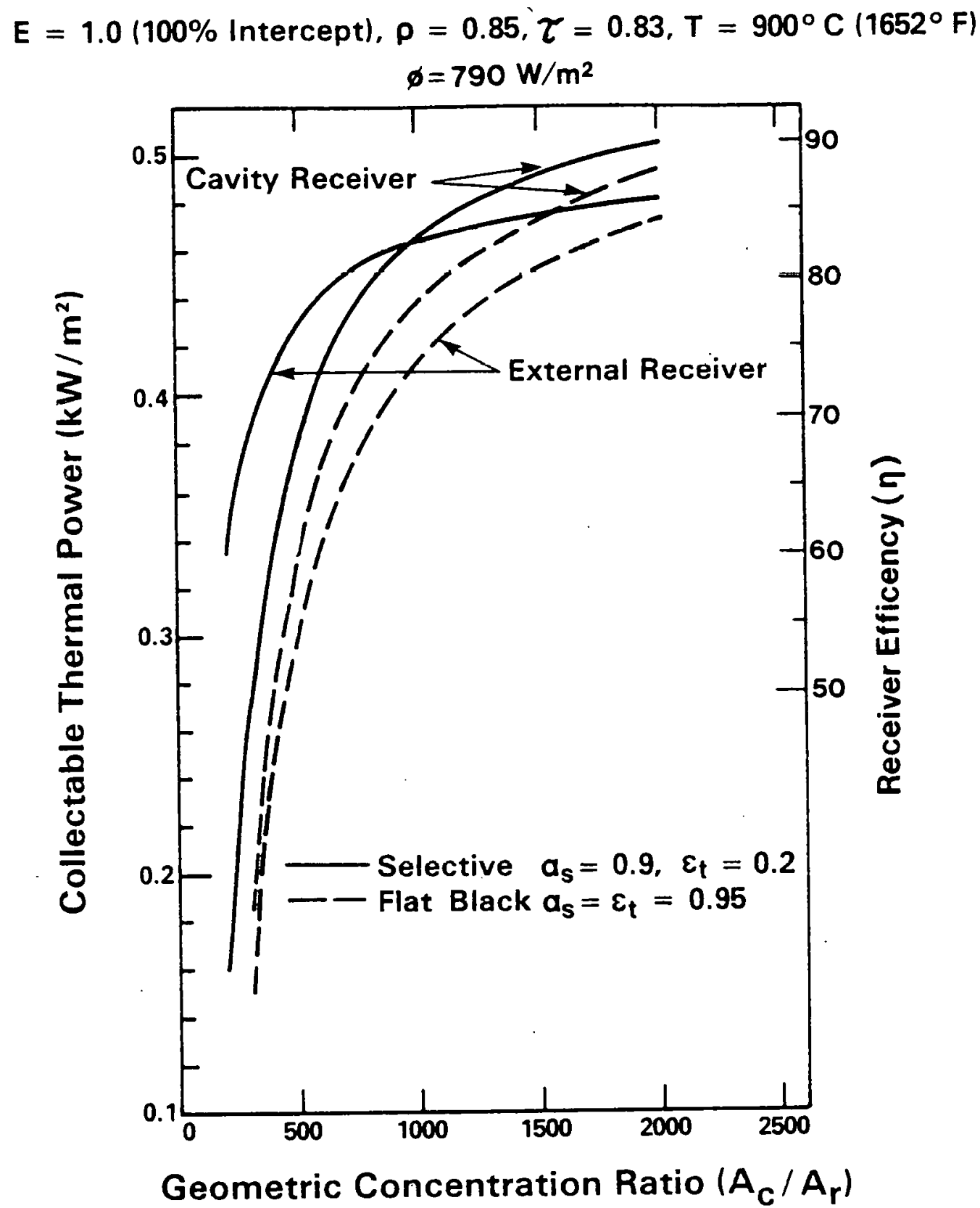

Figure 2-4 Central Receiver Thermal Performance at $900^{\circ} \mathrm{C}$ (Adapted from [26]) 


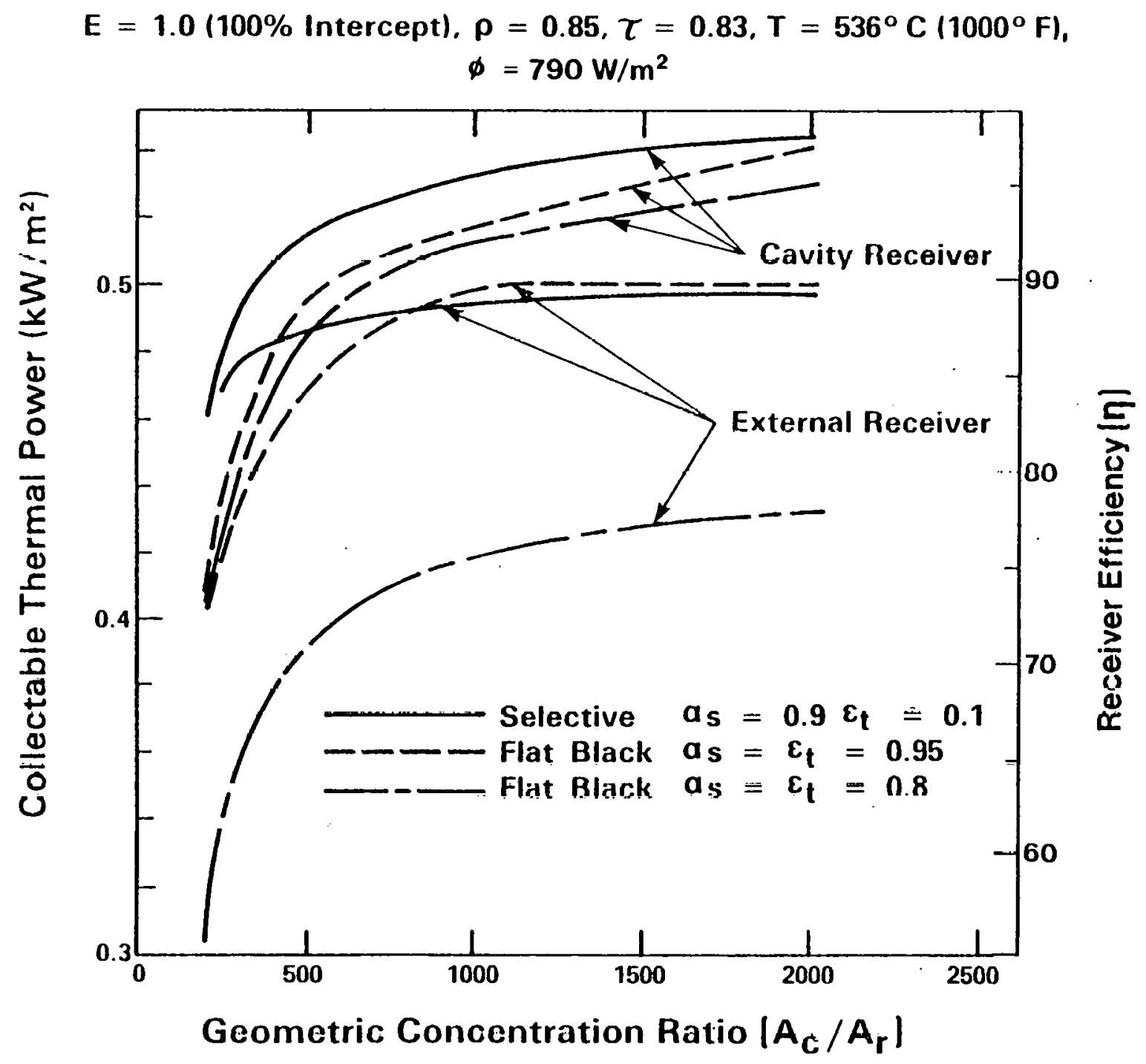

Figure 2.5 Central Receiver Thermal Performance at $536^{\circ} \mathrm{C}$ (Adapted from 126)) 


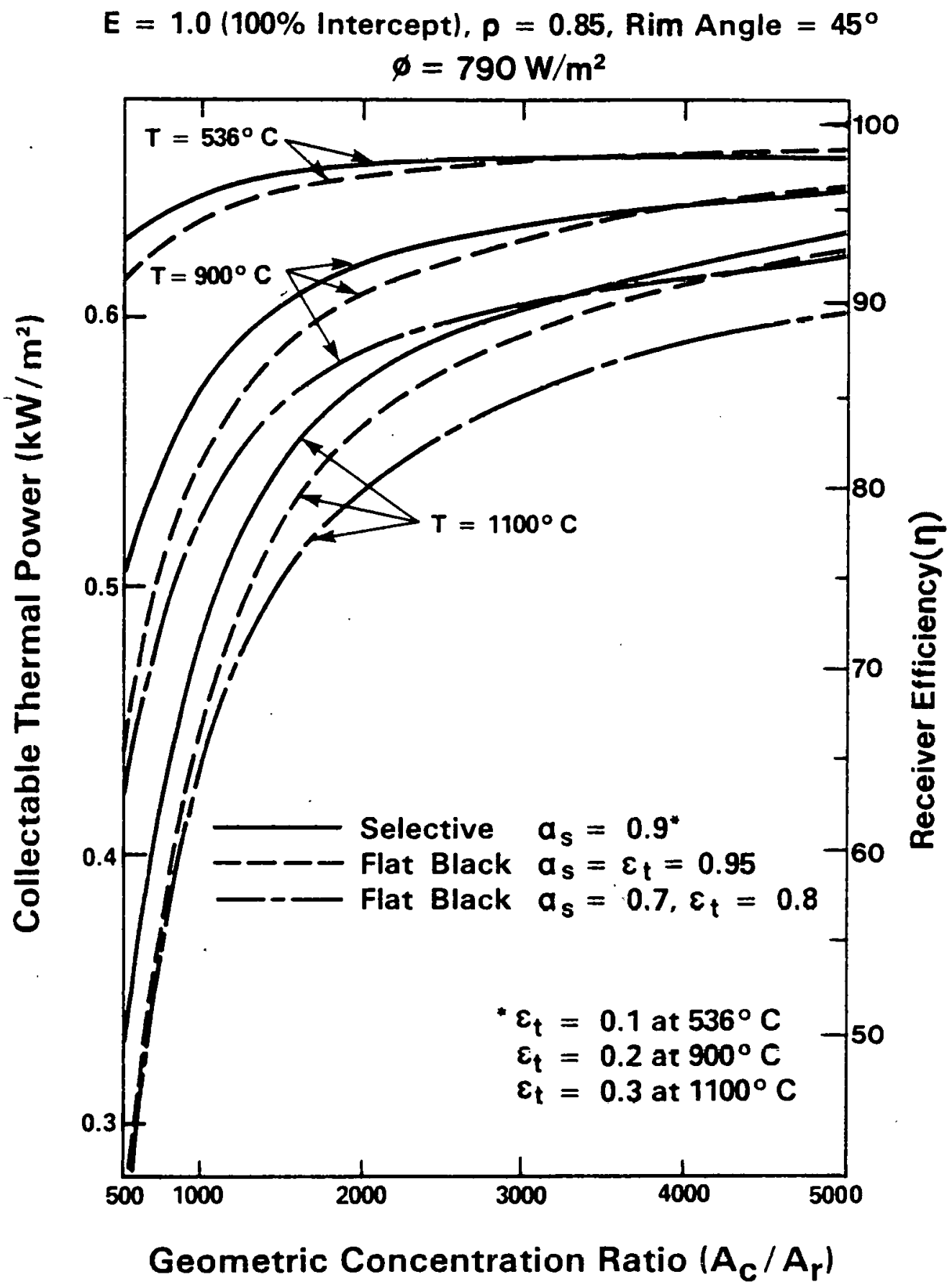

Figure 2-6 Parabolic Dish / Cavity Receiver Thermal Performance (Adapted from [26]) 
$E=1.0(100 \%$ Intercept $), \rho=0.85, \tau=0.69, T=316^{\circ} \mathrm{C}\left(600^{\circ} \mathrm{F}\right)$

$$
\phi=790 \mathrm{~W} / \mathrm{m}^{2}
$$

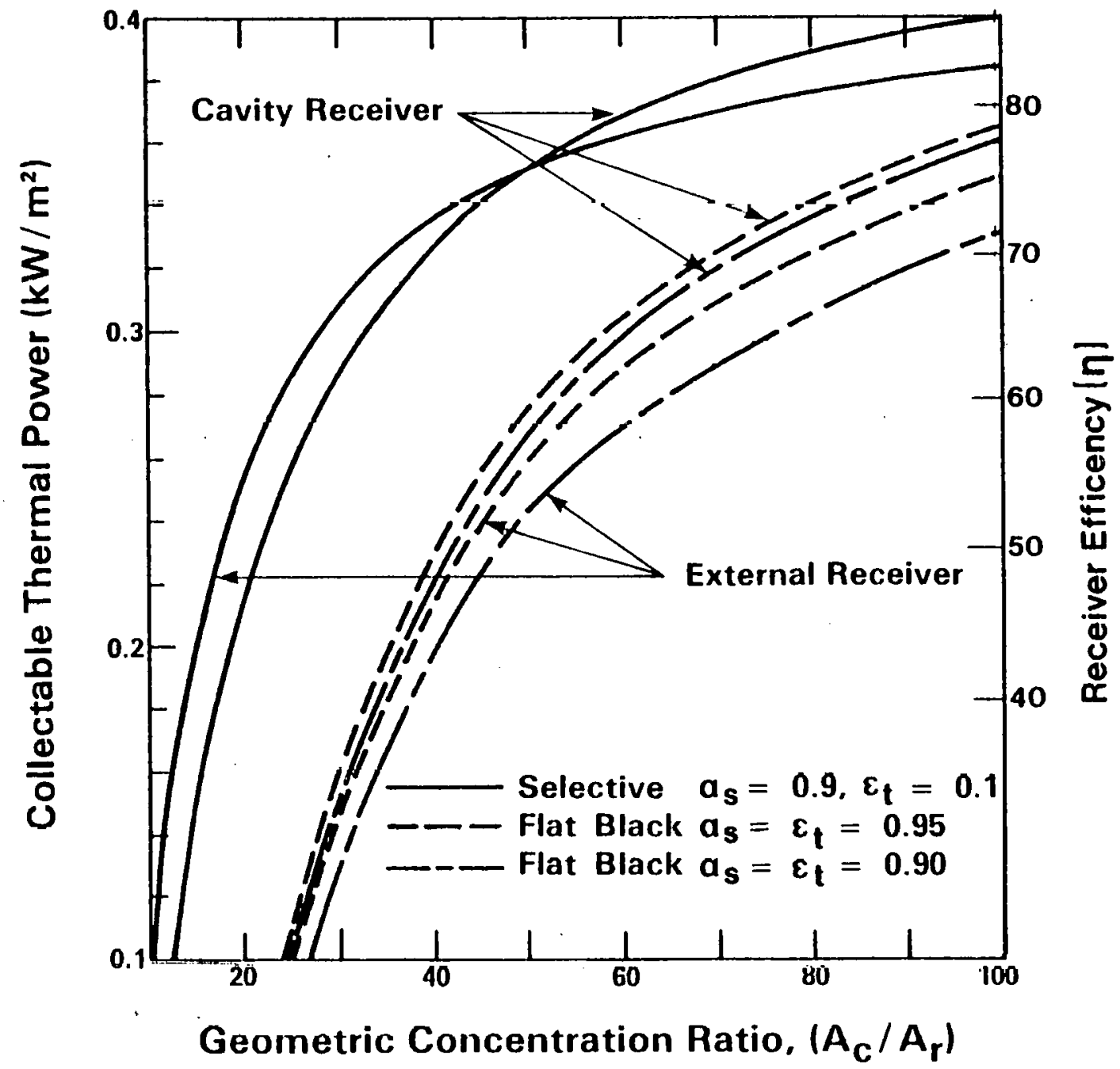

Figuro 27 Paraluolic Tiough (E-W) Thermnl Performanoo (Adapted from [26]) 
Several general conclusions emerge from the optical performance studies.

- The effect of an absorber surface on system performance is a function of system operating conditions. To compare the benefits of absorber surfaces, the distribution of actual operating conditions must be used to assess the differences in system performance at particular operating conditions.

- The total benefit of one absorber surface with respect to another is extremely sensitive to the design operating point, which often depends on factors other than the surface.

- Although an optically selective receiver surface may have only limited benefit for a collector system when it is operating under design conditions, an important effect of such a receiver surface is to improve system performance during off-design conditions such as startup and low insolation periods.

- The merit of the selective coating appears to be inversely proportional to the optical quality of the reflector in a concentrator and may reduce the impact of poor or degraded reflector performance.

- A selective surface provides a buffer for a mismatched collector/heat engine system and tends to moderate the operating temperature sensitivity of system performance.

Table 2-5 summarizes the current understanding of optical performance benefits based on measurement and analysis weighted over the expected operating conditions. This table is an important input to the program benefit analysis, which sets priorities for the development program. Development activities addressing small improvements in receiver performance $(\Delta \eta / \eta \approx 5 \%)$, although eventually of modest interest, will be funded only at a very low level until program goals with greater and more immediate payback are met.

\subsubsection{Cost-Analysis}

The importance in a benefit evaluation of the cost of an absorber surface can be determined by comparing the cost of the receiver surface $\left(\$ / \mathrm{m}^{2}\right)$ divided by the geometric concentration ratio $A_{c} / A_{r}$ to the overall installed cost of the system. Table 2-6 shows that only for low concentration ratio systems or very expensive absorber surfaces is the cost of the absorber surface an important consideration.

\subsubsection{Durability Analysis}

Few data exist to quantify the durability (lifetime) of absorber surfaces. To remedy this deficiency, a rigorous program of experimentation and data analysis will be started as part of the Absorber Surfaces Program. For low temperature systems the durability of properly applied black chrome appears to be very good; however, as lower-cost materials are developed, a direct 


\section{Receiver Performance Comparison for Selective vs. Nonselective Absorber Surfaces*}

\section{Collector Design}

Flat Plate

Evacuated Tube

E-W Oriented Parabolic Trough with External Receiver

E-W Oriented Parabolic Trough with Cavity Receiver

E.W Oriented Parabolic Trough with External Receiver

10 MWe External Central Receiver $(200-400 x)$

External Central Recelvers $\mid>700 x)$

Cavity Parabolic Dlsh $(>1000 x)$

Cavity Parabolic Dish (> 1000x)
Receiver

System

Operating Temperature

( $\left.{ }^{\circ} \mathrm{C}\right)$

$<100$

$<200$

$=300$

$\approx 300$

$\approx 500$

550

550

$500-300$
Performance Performance

$(\Delta \eta)$

$0.1-0.15$

$0.1-0.15$

0.2

0.1

$>0.2$

$0.1 \cdot 0.16$
$15-20$

$(\Delta \eta / \eta, \%)$

up to 100

up to 100

$50-150$

20-25

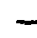

* From $a_{s}=\varepsilon_{t}=0.95$, to $a_{s}=0.9$ and $\varepsilon_{t}\left(\leq 600^{\circ} \mathrm{C}\right)=0.1, \varepsilon_{t}\left(900^{\circ} \mathrm{C}\right)=0.2$

$$
\varepsilon_{t}\left(1100^{\circ} \mathrm{C}\right)=0.3 ; Q_{\text {cond }}=Q_{\text {conv }}=0
$$

* Referenced to $\eta$ for a nonselective absorber surface

Table 2.5 


\section{Impact of Absorber Surface Cost on System Cost}

$\begin{array}{lcccc}\text { Application } & \mathbf{A}_{\mathbf{C}} / \mathbf{A}_{\mathbf{r}} & \begin{array}{c}\text { Installed System } \\ \mathbf{C o s t}^{\mathbf{1}}\left(\mathbf{\$} / \mathbf{m}^{2}\right)[29]\end{array} & \begin{array}{c}\text { Absorber Cost } \\ \left(\$ / \mathbf{m}^{2}\right)\end{array} & \begin{array}{c}\text { Absorber Cost } \\ \text { Impact }\end{array} \\ \text { Flat Plate } & 1 & 150-450 & 10-22 & 2.2-13.3 \\ \text { Evacuated Tube } & 1.5-3 & 200-500 & 15-40 & 1.0-13.3 \\ \text { Parabolic Trough } & 2-70 & 200-475 & 20-40 & <1 \\ \text { Parabolic Dish } & >1000 & 500-1500 & \text { up to } 1000 & <1 \\ \text { Central Receiver } & 400-4000 & 100-600^{(4)} & \text { up to } 1000 & <1\end{array}$

' The larger number reflects current state of technology based on collector area

2 Based on reflector area

${ }^{3}$ Absorber cost impact $=$ (absorber cost $/$ installed system cost) $\times A_{r} / A_{C}$

4 Estimate of early commercialization based on Barstow facility 
tradeoff with lifetime may be observed. At temperatures greater than $300^{\circ} \mathrm{C}$, the durability of all receiver surfaces must be evaluated carefully.

\subsection{PROGRAM COST/BENEFIT}

An important guideline for program management is the justifiable near-term expenditure for a federally funded $R \& D$ effort based on the future value of the benefits derived from that program.

The value of a program cannot be computed analytically or accurately. However, with conservative assumptions meaningful limits can be placed on expenditures for development.

The present value (PV) of absorber surface $R \& D$ can be expressed as summations over all systems $j$ and future years $n$ of the benefit of perforllince, cusl, dul durability 1mp rovements:

$$
P V=\Sigma_{j} \Sigma_{n}\left[\Omega_{j} \Delta \eta_{j} / \eta_{j}+k_{j} \Delta p_{j}+\frac{l_{j}}{\left(L_{j}-l_{j}\right) L_{j}} k_{j} p_{j}\right] \frac{V_{j n}{ }^{E} n}{(1+d)^{n+7}}
$$

where $\quad v_{j n}=$ value of unit energy delivered

$E_{j n}=$ quantity of energy delivered

$\mathrm{d}=\mathrm{d}$ iscount rate

$p_{j}=$ percentage of capital cost associated with the absorber surface

$k_{j}=$ percencage of energy cusl associated with capital cost

$\ell_{1}=$ improvement in measured absurber surface life time from current io expecited

$T_{1}=$ experted absorber surface lifetime $\Delta \mathrm{p}_{\mathrm{j}}=\begin{gathered}\text { reduction in percentage of capital cost from } R \& D \\ \text { efforl }\end{gathered}$

$\Omega_{j}=$ overall system thermal efficiency

$\eta_{j}=$ receiver efficiency

$\Delta \eta_{j}=$ improvement in receiver efficiency

The first term describes the benefit ascribed to performance improvements, assuming that no capital or operation and maintenance (O\&M) costs are associated with the improvement. This term is the product of the absolute improvement in overall system efficiency resulting from an improvement in receiver performance and the total value of the energy produced in year $n$ discounted to its present value.

The second term is the change in the total cost of energy supplied in year $n$ by system $j$ as a result of the reduction (through $R \& D$ ) of the absorber surface cost, assuming no change in performance. The factor $k_{j}$ accounts for $0 \& M$ costs. 
The final term attempts to describe conservatively the value of durability by assuming that a fraction of the absorber surface cost (1/lifetime) will have to be paid each year. The value of durability improvements is then set equal to the benefit of improving the lifetime of a particular absorber to an acceptable value ( -30 years). This estimate ignores the cost of disassembling and reassembling the system and of shipping the receiver surface to a distant location for reprocessing, which may be many times the original absorber surface cost.

A semiquantitative analysis of program benefit follows, based on the utilization of six systems:

- hot water and low-temperature heat

* flat plate $(j=1)$

- agriculture and industrial process heat

* evacuated tube $(j=2)$

* parabolic trough (3)

* parabolic dish (4)

- solar thermal electric

* small central receiver $(j=5)$

$* \quad$ large central receiver (6)

$E_{j n}$ is taken from Figure 2-8, which is based on a table of market penetration study results [28], and weighted toward the MITRE SPURR numbers. Assuming each of the solar electric options receives one half of the solar thermal penetration and each process heat option accounts for one third of that penetration, the analysis can be completed using parameters previously evaluated (Table 2-5) and assuming that $\mathrm{k}_{\mathrm{j}}=0.9, \mathrm{~V}_{\mathrm{j}}=\$ 2 / \mathrm{MBtu}$, and $\mathrm{d}=0.10$. Because quantitative lifetime data are not available, the third term will not be evaluated.

The present value (1978) of the research effort is calculated for energy delivered from 1985 to 2020. This exercise indicates that even small improvements in state-of-the-art absorber surface performance and cost can have a very large potential benefit. The most critical parameter in equation (4) is the discount rate, which is philosophical rather than technical. Although a $10 \%$ discount rate is a standard economic assumption and leads to a program value of $\$ 760$ million (Table $2-7$ ), varying the value for this parameter from $15 \%$ to $5 \%$ leads to a range for the present value of absorber surface R\&D from $\$ 400$ million to $\$ 3$ billion. Assuming that as little as $1 \%$ of the future benefit is an allowable near-term $R \& D$ expense, an $\$ 8$ million Federal contribution to the program is easily justified and the industry's contribution will raise the total program expenditure to a higher value.

Th1s performance and cost analysis indicates that low temperature absorber surfaces have highest priority, followed by absorber surfaces for parabolic troughs and higher temperature selective absorbers for low concentration ratio systems. Very high-temperature absorber surfaces have lowest priority. Absorber surfaces for all applications require improved durability, and testing. 


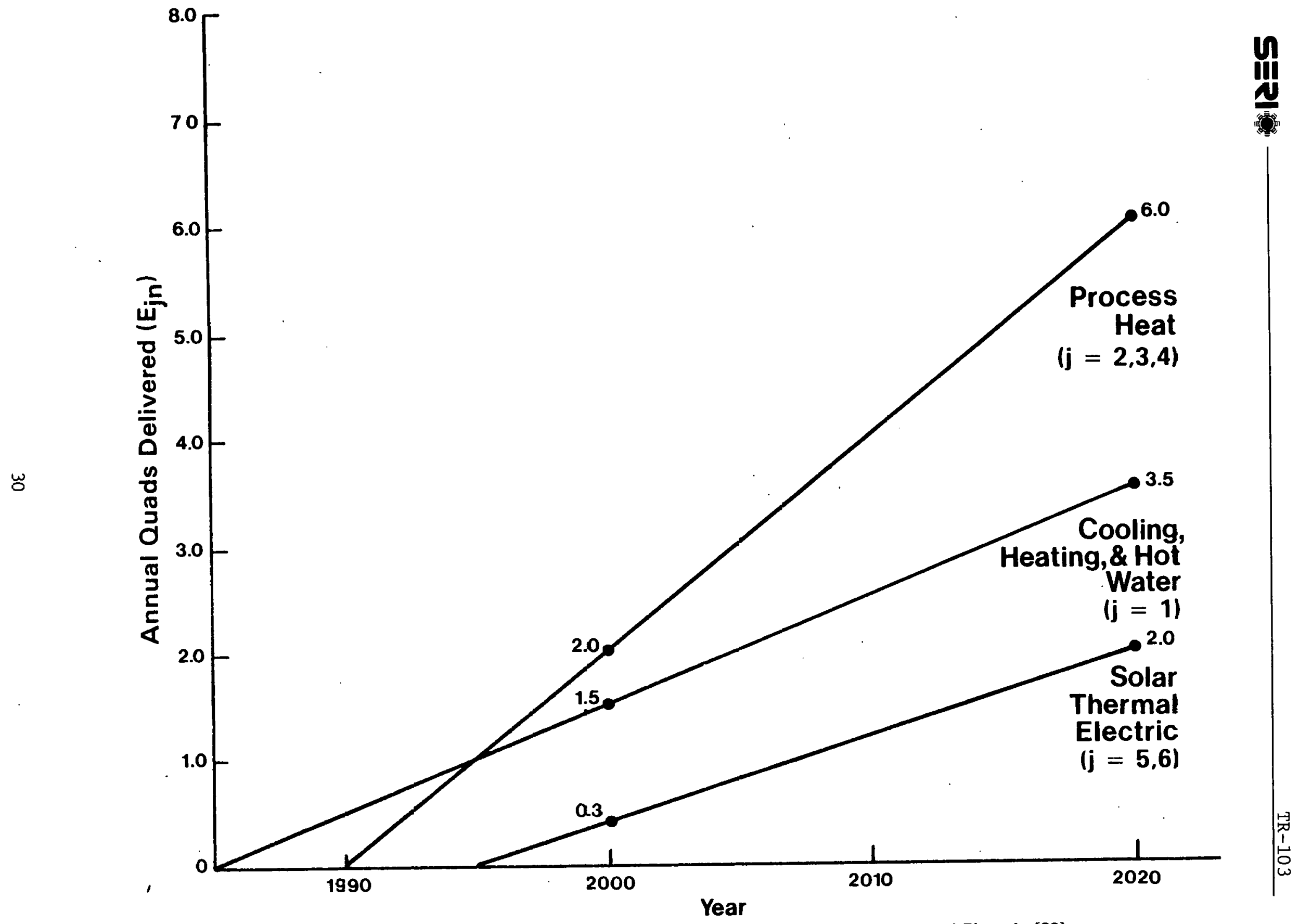

Figure 2-8 Market Penetration for Solar Heating. AIPH and Solar Thermal Electric [28] 


\section{Summary of Benefits of Absorber Surface R\&D*}

\begin{tabular}{|c|c|c|c|c|c|}
\hline j System & $\Omega_{\mathbf{j}}^{[29]}$ & $\Delta \eta_{\mathbf{j}} / \mathbf{\eta}_{\mathbf{j}}$ & $\Delta \mathbf{p}_{\mathbf{j}}$ & $E_{j n}$ & $P V_{j}^{(3)}(\$ M)$ \\
\hline 1 Flat Plate $\left(<100^{\circ} \mathrm{C}\right)$ & .35 & $.04^{(1)}$ & $.03^{(1)}$ & $\mathrm{n} / 10$ & 390 \\
\hline $\begin{array}{r}2 \text { Evacuated Tube } \\
\left(100-200^{\circ} \mathrm{C}\right)\end{array}$ & .45 & $.04^{(1)}$ & $.03^{(1)}$ & $(n-5) / 15(n>5)$ & 160 \\
\hline $\begin{array}{l}3 \text { Parabolic Trough } \\
\left(200-500^{\circ} \mathrm{C}\right)\end{array}$ & .2 & $.2^{(2)}$ & o & $(n-5) / 15(n>5)$ & 150 \\
\hline $\begin{array}{l}4 \text { Parabolic Dish } \\
\left(>500^{\circ} \mathrm{C}\right)\end{array}$ & .4 & $.01^{(2)}$ & 0 & $(n-5) / 15(n>5)$ & 10 \\
\hline $\begin{array}{l}5 \text { Small Central Receiver } \\
\left(500^{\circ} \mathrm{C}\right)\end{array}$ & .6 & $.05^{(2)}$ & o & $(n-10) / 25(n>10)$ & 40 \\
\hline $\begin{array}{l}6 \text { Large Central Receiver } \\
\left(500^{\circ} \mathrm{C}\right)\end{array}$ & .6 & $.01^{(2)}$ & 0 & $(n-10) / 25(n>10)$ & 10 \\
\hline
\end{tabular}

* Terms defined in equation (4)

(1) Compared to black chrome; $\Delta a_{s} \simeq .01 ; \Delta \varepsilon_{t} \simeq .01 ; 3 / 4$ reduction in current cost of $\$ 15 / \mathrm{m}^{2}$ at $5 \%$ of system cost.

(2) Compared to Pyromark.

(3) Present Value ( $\$ 1978$ ) of improvements in receiver performance for specific systems calculated from equation (3).

Table 2-7 


\subsection{PROGRAM GUIDELINES}

The previous section has set the priorities for the Absorber Surfaces Program and has provided a conservative estimate of $\$ 8 M$ for the budget of a multiyear effort beginning in FY79. The Absorber Surfaces Program will continue to evaluate applications for significant potential benefits from absorber surface R\&D and will assist the commercial sector in developing and testing appropriate absorber surfaces. Backup surfaces will be identified and developed where none exist, and suitable coatings will be made available for demonstration projects. The general strategy requires the greatest Federal involvement in the high-risk $R \& D$ and definition phases and increasing industry involvement throughout the commercialization phases. The relatively large number of $R \& D$ contracts in the initial phases is reduced as the development effort matures, so that government support of (at most) two concepts for a given application will persist to the commercialization phase.

To meet the dual goals of short-term commercialization of desirable R\&D components and long-range improvements in solar technologies, the Absorber Surface Program will adopt the general strategy of funding 1ndustry for applied $R \& D$ and universities for the basic $R \& D$ appropriate to support the development activities.

The role of the national laboratories will be to take the lead in program definition/justification, including the industrial and university components. The national laboratories, though not precluded from participating in R\&D will carry out support activities integrated with industrial and university $R \& D$. The current DOE and national laboratory responsibilities for absorber surface R\&D are listed in Table 2-8, within the framework of the program plan proposed in Section 3 . 


\section{Present DOE and National Laboratory Absorber Surface Responsibilities}

\begin{tabular}{|c|c|c|c|}
\hline $\begin{array}{c}\text { Development } \\
\text { Objective }\end{array}$ & $\begin{array}{c}\text { DOE Lab } \\
\text { Responsibility }\end{array}$ & $\begin{array}{c}\text { DOE R\&D } \\
\text { Responsibility }\end{array}$ & $\begin{array}{l}\text { DOE } \\
\text { User }\end{array}$ \\
\hline $\begin{array}{l}\text { Low Temp: } \\
\text { Evacuated Tube, } \\
\text { Flat Plate, and } \\
\text { Passive }\end{array}$ & $\begin{array}{l}\text { LASL } \\
\text { LBL }\end{array}$ & $\begin{array}{l}\text { Solar Heating } 8 \\
\text { Cooling R\&D } \\
\text { [SHACRD] }\end{array}$ & Demonstrations \\
\hline Black Chrome & $\begin{array}{l}\text { LASL } \\
\text { Sandia-Alb }\end{array}$ & $\begin{array}{l}\text { AlPH } \\
\text { Small Power } \\
\text { Systems }\end{array}$ & $\begin{array}{l}\text { AIPH } \\
\text { Small Power } \\
\text { Systems }\end{array}$ \\
\hline $\begin{array}{l}\text { Intermediate } \\
\text { Temperature } \\
\text { Selective Absorbers }\end{array}$ & $\begin{array}{l}\text { SERI } \\
\text { Sandia-Alb } \\
\text { Sandia-Liv }\end{array}$ & $\begin{array}{l}\text { Advanced Solar } \\
\text { Thermal Technology } \\
\text { [ASTT] }\end{array}$ & $\begin{array}{l}\text { Large Power Systems } \\
\text { Distributed Systems }\end{array}$ \\
\hline $\begin{array}{l}\text { High Temperature } \\
\text { Absorber Surfaces }\end{array}$ & SERI & ASTT & $\begin{array}{l}\text { Large Power Systems } \\
\text { Distributed Systems }\end{array}$ \\
\hline $\begin{array}{l}\text { Basic \& Generic } \\
\text { Research }\end{array}$ & SERI & BES & \\
\hline
\end{tabular}

Table 2-8 
THIS PAGE INTENTIONALLY LEFT BLANK 
SECTION 3.0

NATIONAL PROGRAM PLAN

\subsection{OVERALL STRATEGY AND FUNDING}

The Absorber Surface Program consists of program management (Section 3.2) four development activities (Section 3.3), and four supporting functions (Sections 3.4-3.7).

The four developmental activities address: improved durability and costeffectiveness of low-temperature selective absorber surfaces for passive, flat-plate, and evacuated tube collectors to $200^{\circ} \mathrm{C}$ (Section 3.3 .1 ); commercial black chrome and an identified alternate selective surface for applications to $400^{\circ} \mathrm{C}$ (Section 3.3.2); intermediate-temperature $\left(400-700^{\circ} \mathrm{C}\right.$ ) selective absorbers (Section 3.3.3); and absorber surfaces for high temperatures $\left(>700^{\circ} \mathrm{C}\right)$ (Section 3.3.4). The selection of temperature regimes for the goals is of necessity somewhat arbitrary. The choices were determined by adding an approximate $100^{\circ} \mathrm{C}$ buffer to operating temperatures for generic applications. Low-temperature surfaces are assumed to operate to $100^{\circ} \mathrm{C}$ based on cooling and process heat requirements, and the stagnation temperature for most low concentration ratio systems is approximately $200^{\circ} \mathrm{C}$. The $300^{\circ} \mathrm{C}$ operating temperature for black chrome is based on present single axis tracking system needs, and the transition from intermediate- to high-temperature regimes is based on the present materials limitation for the steam heat engine cycle $\left(560^{\circ} \mathrm{C}\right)$.

The four supporting functions are: optical measurememtns, durability testing, and component evaluation (Section 3.4); systems analysis (Section 3.5); data base (Section 3.6); and basic and generic research (Section 3.7).

Estimates of the funding levels in constant FY78 dollars for these nine major activities are shown in Figure 3-1. All dollar amounts are contingent on the availability of funds. The benefit analysis indicates that an approximate apportionment of development funds for low-, intermediate-, and high-temperature systems might logically be in the ratio $9: 3: 1$; however, the plan assumes a ratio of $3: 3: 1$ because of the longer history of low-temperature absorbers and an established commercial industry for them. Each major support and development activity is described in detail in the following sections.

\subsection{PROGRAM MANAGEMENT}

The overall coordination of the Absorber Surface Program will be the responsibility of the Materials Branch of the Research Division at SERI. The Special Programs office at SERI assumed technical management responsibility on April 1, 1978 for the intermediate-temperature selective surface and high-temperature absorber surface development activities funded by ET. These activities were previously monitored by JPL/NASA-Lewis and managed by the Advanced Solar Thermal Technology Branch. Los Alamos Scientific Laboratory currently has technical management responsibility for absorber surfaces R\&D funded by SHAC in DOE/CS (passive, heating and cooling, and process heat applications). 


\section{Overview of Estimated Program Funding (\$k)}

\begin{tabular}{|c|c|c|c|c|c|c|c|}
\hline & FY 78 & 79 & 80 & 81 & 82 & 83 & \begin{tabular}{|c|} 
Estimated \\
Total \\
FY79-FY83
\end{tabular} \\
\hline Program Management & 120 & 192 & 160 & 160 & 140 & 110 & 760 \\
\hline Low Temperature Absorber Surfaces $\left(<200^{\circ} \mathrm{C}\right)$ & 580 & 257 & 400 & 400 & 200 & 200 & 1460 \\
\hline Black Chrome $\left(<400^{\circ} \mathrm{C}\right)$ & 200 & 255 & 250 & 100 & 100 & 100 & 805 \\
\hline $\begin{array}{l}\text { Intermediate Temperature Selective Absorber } \\
\text { Surfaces }\left(400-700^{\circ} \mathrm{C}\right)\end{array}$ & 180 & 295 & 250 & 250 & 250 & 100 & 1145 \\
\hline High Temperature Absorber Surfaces $\left(>700^{\circ} \mathrm{C}\right)$ & 70 & 70 & 100 & 100 & 100 & 100 & 470 \\
\hline DEVELOPMENT SUBTOTAL & 1030 & 877 & 1000 & 850 & 650 & 500 & 3880 \\
\hline Measurements, Durability and Component Testing & 381 & 425 & 530 & 305 & 305 & 85 & 1650 \\
\hline Systems Analysis & 30 & 75 & 75 & - & - & - & 150 \\
\hline Data Base & 10 & 45 & 70 & 70 & 70 & 10 & 265 \\
\hline Basic and Generic Aesearch & 336 & 335 & 250 & 250 & 250 & 250 & 1335 \\
\hline SUPPORT SUBTOTAL & 687 & 880 & 925 & 625 & 625 & 345 & 3400 \\
\hline TOTAL & 1840 & 1950 & 2085 & 1635 & 1415 & 955 & 8040 \\
\hline
\end{tabular}


Sandia-Albuquerque Laboratory has technical management responsibility for the black chrome development effort funded by the Small Power Systems Branch in DOE/DST. The technical management responsibilities will be maintained and an Absorber Surface Coordinating Council will be created. The coordinating council will be formed from representatives of SERI, Sandia-Albuquerque, LASL, JPL, and Sandia-Livermore with responsibility to: (a) maintain a balance of funds between development and support activities and among universities, industry, and national laboratories; (b) promote communication through interaction with related programs and interested parties; (c) establish topical meetings to address specific program and industry needs; and (d) ensure program continuity.

The technical management of each developmental activity will have continued responsibility to: (a) monitor contractor technical and administrative activities as defined in precise statements of work; (b) formulate, develop, and issue solicitations to initiate subcontracted efforts required to achieve program plan goals; (c) evaluate solicited and unsolicited proposals, convene review panels, select contractors, negotiate agreements, and award contracts; and (d) review final reports from completed contracts.

Within the program, communication will be maintained by:

- brief ( $3-5$ page) quarterly reports, due to the technical manager five working days before the end of April, June and October. Highlights of these quarterly reports and support activity highlights, budget information, and program decisions will be published by SERI as quarterly program status reports.

- a conference to be held annually in mid-January to be devoted to absorber surfaces and accessible to the entire scientific community. Each DOE contractor will present a review of research progress for the previous year.

- one-page monthly letter reports due at the end of each month not already covered by the quarterly reports or the conference presentation. These reports will aid the contractor and the technical manager in project planning and will not be distributed.

- a final report which will be prepared by each contractor at the conclusion of the contract. The report will be reviewed and a summary will be distributed to the other program participants.

- an annual review of the program plan with the appropriate DOE personnel in mid-June of each year to agree on the following fiscal year operating plan and to make budgetary inputs to the two-year budget cycle.

\subsection{DEVELOPMENT AND DEMONSTRATION}

The systems benefit analysis has set priorities for development and demonstration activities in decreasing order as follows: 
- $\quad$ low-cost selective absorbers (to $200^{\circ} \mathrm{C}$ ),

- black chrome and an alternative (applications to $400^{\circ} \mathrm{C}$ ),

- intermediate-temperature selective absorbers $\left(400\right.$ to $\left.700^{\circ} \mathrm{C}\right)$, and

- high-temperature absorber surfaces $\left(>700^{\circ} \mathrm{C}\right)$.

The degree and type of government support will be determined in each case by the proximity of the commercial market and the importance of the absorber surface to a technical system feasibility demonstration project. For lowtemperature applications where a vigorous market exists, the Absorber Surface Program will assist in, rather than create, new technologies. For highertemperature applications where the market is small and a greater risk is associated with development, a more extensive government funding effort may be needed to create the required technology.

\subsubsection{Low-Cost Selective Absorbers (to $200^{\circ} \mathrm{C}$ )}

A broad-based program in this technology area was created through sections of RFP 22 and PRDA-3 (SHAC R\&D in DOE/CS) in FY77 with funding beginning in FY78 as described in Figure 3-2 and based on a National Program Plan for SHAC R\&D [32]. Because the market for low-temperature absorber surfaces is vigorous and expanding, transition of this activity to a development phase is not anticipated. Continued $R \& D$ support on a range of alternatives, coupled with increased support in determining durability and accelerated lifetime tests, is needed. The progress of the approaches funded through RFP 22 and PRDA-3 will be assessed in late FY79; a decision will be made at that time whether to continue funding of individual ongoing projects, to issue another absorber materials RFY, or a combination of both. By FY82, the transition to a smal1 "innovative concept" R\&D phase should be complete.

Hịh-prioxity R\&D topics:

- reduce cost of absorber surfaces for flat plate collectors without reducing optical performance or durability;

- improve proccoo control;

- assess aváilabilitity of (and develop, if necessary) absorber materials for more cost-effective, second generation collector systems (evacuated tube, all plastic flat plates); and

- assess potential of selective absorbers for passive applications.

Long-range R\&D topic:

- increase solar absorptance from 0.95 to 0.98 , reduce thermal emiltance from 0.1 to 0.05 without sacrificing cost or durability objectives. 


\section{Funding for Identification and / or Development of Low Cost Solar Absorbers for Passive, Flat Plate and Evacuated Tube Receivers (\$k)}

A. Commercial Selective Surfaces Applicable to Copper, Aluminum and Stainless Steel (Berry Solar Products)

B. Solar Selective Absorbers by Electro-Deposition of Paint (DeSoto, Inc.)

C. Selective Paint and Black Chrome Coatings Development (Honeyivell)

D. Improved Solar Selective Coating Stability lOwens - Illinois)

E. Black Germanium Selective Absorber Surfaces (Penn State University)

F. Selective Surfaces by DC Reactive Sputtering ITELIC Corp.)

G. Optical Coatings for Flat Plate Solar Collectors (Honeywell)

H. Absorber Surfaces for Evacuated Tube and Plastic Flat Plate Collectors

I. Other (Follow - On, RFP, or Unsolicited)

TOTAL

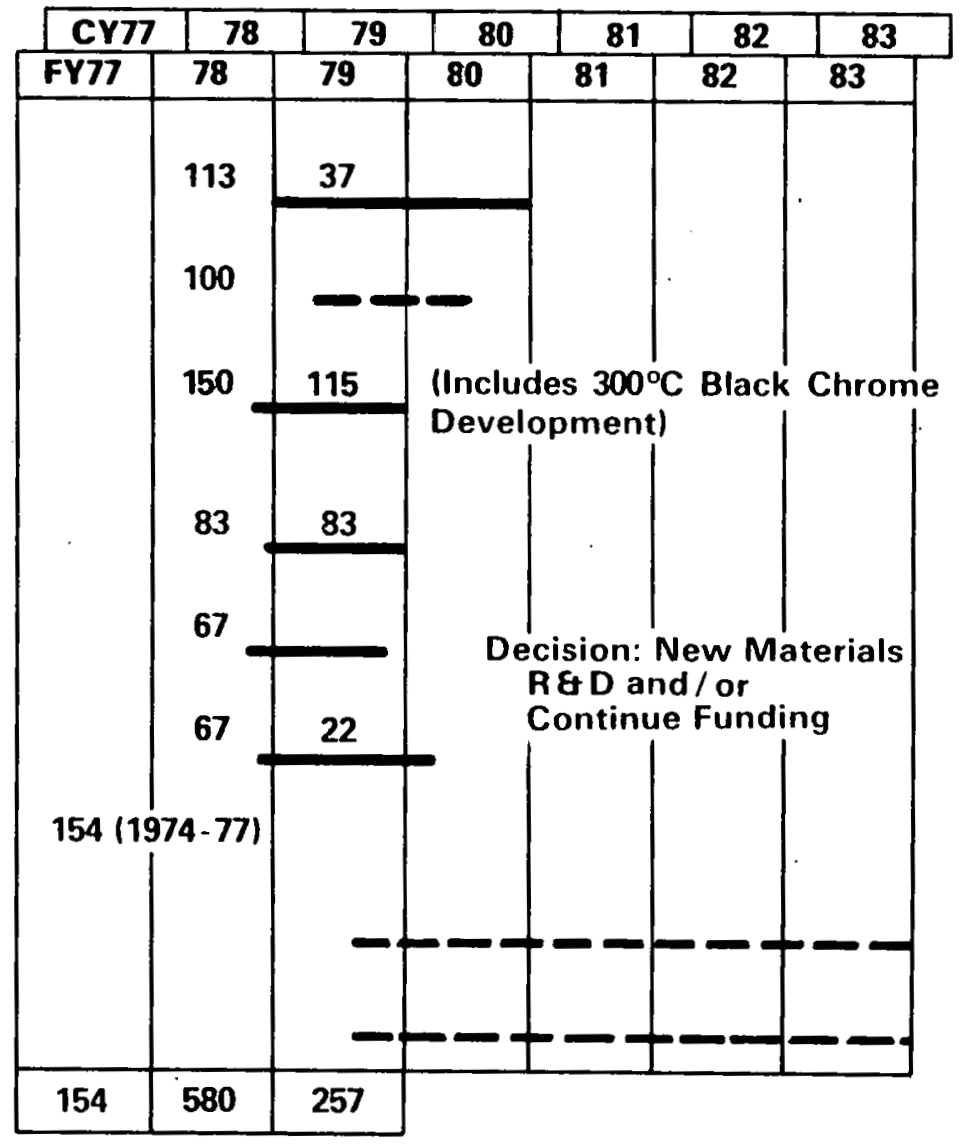

- - Activities plannedi or under negotiation (N) 


\subsubsection{Black Chrome (to $400^{\circ} \mathrm{C}$ )}

Black chrome for single axis tracking applications has reached the commercial phase; however, many degradation and processing questions remain. As indicated in Figure 3-3, R\&D to establish processing parameter limitations for the Harshaw chromonyx electroplating solution is being pursued at Sandia-Albuquerque Laboratories and at Honeywe11. This work will establish the commercial viability of black chrome for single axis tracking collectors by mid- to lateFY79. Considerable private development work is also concentrating on this issue. A small research contract to identify alternatives to black chrome will be funded in mid-FY79. A decision as to the adequacy of black chrome and the need for an alternative will be made in late FY79.

Considerable support for black chrome development will continue in Basic and Generic Research (Section 3.7), to understand the mechanisms of optical absorption and degradation, and in the Measurement and Durability activities (Section 3.4), toward designing suitable durability and accelerated liferime tests.

High-priority R\&D topics:

- establish reproducible processing techniques and identify key process parameters to achieve acceptable optical properties and thermal stability,

- investigate alternative black chrome electroplating; and

- identify backup absorber surface.

Long Range R\&D topic:

- improve solar absorptance to 0.98 while reducing thermal emlltallet

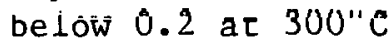

\subsubsection{Intermediate-Temperature Selective Surfaces $\left(400^{\circ} \mathrm{C}\right.$ to $\left.700^{\circ} \mathrm{C}\right)$}

A modest improvement for low concentration ratio external central receiver performance and a critical need for good selective absorber surfaces to extend the operating termperature of single-axis tracking concentrators provide the justification for continued activity in this area. The Energy Technology Program has funded chemical vapor deposition of absorber/reflector stacks, fired organometaliic layers, and vacuum-deposited ceruet films. Vacuum techniques are being explored at a modest level in private industry. In mid FY79 the program will determine the minimum solar absorptance necessary to warrant development. A decision will be made in late FY79 as to which concepts(s) will receive continued support, based on demonstrated thermal and photothermal stability and achievement of progress toward the optical performance goal. One concept will be chosen for development support and a backup will be identified (Figure $3-4$ ). 


\section{Funding for Establishment of Commercial Viability of Black Chrome for Applications To $400^{\circ} \mathrm{C}$ and Identification of an Alternate Absorber Surface (\$k)}

A. Commercial Development of Blach Chrome (Honeywell)

B. Black Chrome Plating and Characterization (Sandia-Alb.)

C. Black Chrome Development (NASA-Lewis)

D. Identify Backup to Black Chrome

(Black Cobalt Processing)

E. Develop Black Chrome Alternative

TOTAL

\begin{tabular}{|c|c|c|c|c|c|c|}
\hline CY7 & 78 & 79 & 80 & 81 & 82 & 83 \\
\hline FYT & 78 & 79 & 80 & 81 & 82 & 83 \\
\hline & IFo & Fundi & $\mathbf{S}$ & ure: & ) & \\
\hline$\sim 150$ & $\sim 200$ & $\sim 200$ & & & & \\
\hline \multicolumn{3}{|c|}{$\sim 200(1974-77)$} & & \multicolumn{3}{|c|}{$\begin{array}{l}\text { Decision: Need to } \\
\text { develop alternative }\end{array}$} \\
\hline 350 & 200 & 255 & & & & \\
\hline
\end{tabular}


Funding for Development of a Selective Absorber for 400-700 ${ }^{\circ} \mathrm{C}$ Applications (\$k)
A. Organometallics !Engelhard Ind.!
B. CVD Semiconductor Metal Stacks (U. of Arizona)
C. Evaporated Cermets (Cornell U.I
D. Semiconductor/Insulator Composites (RCA)
E. Sputtered Films IU. of Ninn.)
F. Black Cobalt (SERI/CSM)
G. Sputtered Cermets (Lincoln Labs)
H. Amorphous Silicon (ANL)
I. Continued Research
J. Development
(I)
(2)
TOTAL

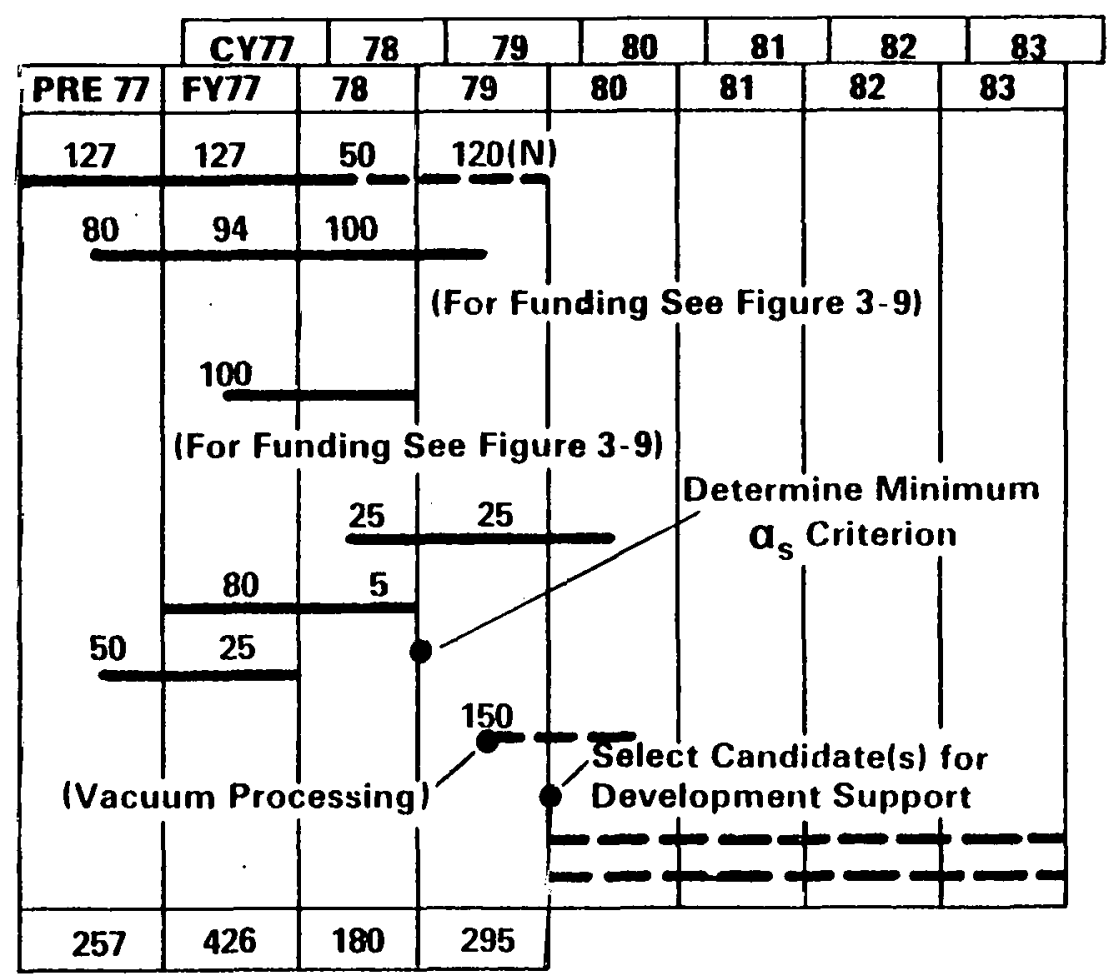

Figure 3-4 
High-priority R\&D topics:

- vacuum, CVD, or electrodeposition processing of foils and investigation of geometric limitations of applying foils, thermal conductance losses across bonding layer, availability of high-temperature bonding materials, and development of bonding techniques for on-site application. Vacuum-processed films (cermets, AMA-like interference stacks) have demonstrated promising optical properties and thermal stability so that the processing effort will be initiated using vacuum techniques to produce absorber surfaces.

- extend operating temperature range and optical properties of absorber surfaces that can be applied on-site (paints, chemical conversion surfaces, organometallics).

Long-range R\&D topics:

- determine degradation mechanisms of developmental absorber surfaces, and

- increase solar absorptance to greater than 0.97 through understanding of material limitations.

\subsubsection{High-Temperature Coatings $\left(700^{\circ} \mathrm{C}\right)$}

The impact of absorber surfaces on the performance of high-temperature receivers is likely to be small because the system concentration ratios w1ll be relatively large and cavity receivers may be used. In the long term improvement by a few percentage points in a receiver's optical performance will be important, so that a small effort to consider optimum cavity surfaces and stable high solar absorptance surfaces (using techniques such as plasma spray coating) is justified. In addition, a small effort in analyzing the physical effect of high photothermal fluxes on receiver structure surfaces will be started (Figure 3-5).

High-priority R\&D topics:

- improved adhesion (thermal shock) and in situ curing,

- study of photothermal stability, and

- study of protection properties.

Long-range R\&D topic:

- stable, high-absorptance ( $\left.\bar{\alpha}_{\mathrm{S}} \geq 0.98\right)$ paints, plasma spray coatings and treated materials of construction. 


\section{Funding for Investigation of Thermophysical Properties of High Temperature Receiver Surfaces and Identification of Surfaces for Temperatures Greater Than $700^{\circ} \mathrm{C}$ (\$k)}




\subsection{OPTICAL MEASUREMENTS, DURABILITY TESTING, AND COMPONENT EVALUATION (Figure 3-6)}

\subsubsection{Optical Measurements}

Measured optical properties of absorber surfaces are required for the following purposes:

- engineering design,

- hardware verification and control,

- durability test evaluation, and

- coating development and analysis.

The optical measurements support in the Absorber Surfaces Program consists of four activities:

- determination of appropriate optical measurements,

- development of standards to ensure that research measurements are comparable,

- identification or development of specialized optical masurement equipment where necessary, and

- independent measurement (qualification) of surfaces developed within the program.

The two absorber surface optical properties essential for receiver design are the solar absorptance and thermal emittance over the range of operating temperatures. The complete characterization of an absorber surface requires a bidirectional reflectance measurement over the spectral range from 0.25 to $25 \mu \mathrm{m}$; however, this measurement is impractical for all but the most specialized applications.

A Solar Optical Materials program planning committee has been established. Scientists from SERI, JPL, Sandia-Albuquerque, Battelle, and NBS are participants. This group is evaluating the importance of temperature, choice of solar spectrum, retroflectance, and polarization on the optical characterization of absorber surfaces. In addition it will determine appropriate measurements for each of the four activities requiring optical data.

For R\&D purposes (for the evaluation of absorber surfaces for flat or singly curved external receivers and the first approximations to cavities), the directional hemispherical reflectance measurement is needed to determine solar absorptance. An Edwards-type integrating sphere attachment to an NIR-VIS-UV spectrophotometer will make this measurement. If the researcher has access to only near-normal hemispherical or specular reflectance measurements, then the program support activity will complement those measurements with directional 


\section{Funding for Optical Measurements, Durability Testing and Component Evaluation (\$k)}
A. Measuremert Definition and Standands INBS, SERI, JPL, Sandia-Alb. PNLI
B. High Temperature Measurements of $a_{s}$ and $\varepsilon_{t}$
C. Program Level Qualification Measurements
D. Program Level Durability Tests (IITRI. etc.)
E. Durability Tes.t Definition (Lockheed)
F. SERI Durability Testing and Component Evaluation
G. Durability Test Definition
H. STTFUA Phatothermal Tests
I. Field Data Analysis
TOTAL.

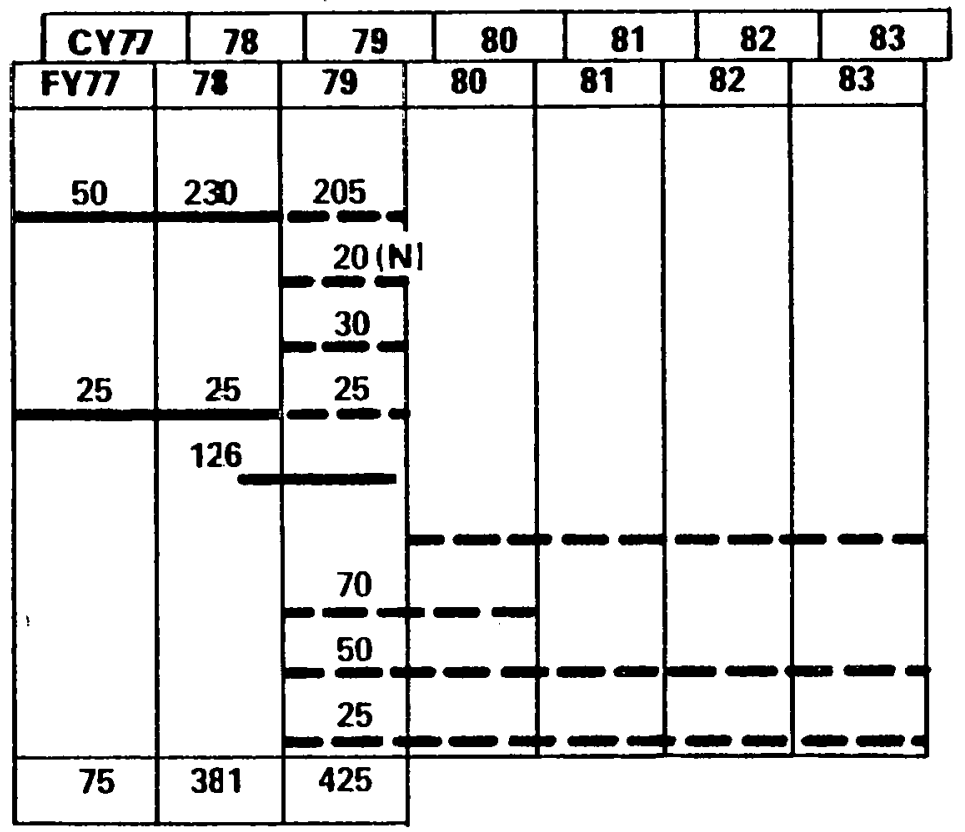

Figure 3-6 
hemispherical measurements contracted at a commercial facility or at one of the participating national laboratories.

Based on an evaluation of the effect of temperature, it may be possible to decouple high temperature and optical measurements in the research mode. With the exception of some semiconductor coatings, the solar absorptance of most materials is not very temperature-dependent. At the R\&D level a simple means of determining whether the absorptance of a coating is temperature-dependent will suffice. This could be done at two or three wavelengths in the solar spectrum by using a simple laser reflectometer device. The program will identify a facility for this measurement and will also identify a facility to do the complete measurement of spectral directional hemispherical reflectance at expected operating temperature for program level evaluation.

Total normal thermal emittance can be calculated using spectral directionalhemispherical reflectance data in the IR. Total hemispherical thermal emittance can be determined calorimetrically.

The working group will publish a list of facilities that can make solar absorptance and thermal emittance measurements.

NBS will continue activities to evaluate optical measurement facilities and to develop standards.

Inexpensive techniques for in-line process control of large area flat plate solar absorbers will be investigated as part of the measurements definition activity.

SERI will take the lead in identifying or developing specialized equipment, and an RFP for independent evaluation of absorber surfaces is expected to be issued.

\subsubsection{Durability Testing}

Durability testing is required at three levels:

- testing at the research level by the developer to establish the inherent durability and to evaluate the effects of materials and/or process variations;

- testing at the program level (which includes basic research into mechanisms of degradation, in order to define accelerated lifetime tests) by an independent laboratory to corroborate the limits to coating utilization; and

- evaluation and qualification tests by the ultimate user.

The Absorber Surface Program is responsible for the first two activities and should provide major guidance to the third.

During early FY79, coating development contractors will prepare durability test plans for review by the Absorber Surface Coordinating Council. This 
activity will result in durability testing guidelines in mid FY79. Requirements for independent durability testing will be defined during FY79 and a contractor selected to do the testing in late FY79.

A program will be initiated in FY79, in cooperation with the Solar Thermal Test Facility Users Association, to assess the photothermal stability of absorber surfaces emerging from advanced development.

\subsubsection{Component Evaluation}

Early work by NASA-Lewis and Sandia-Albuquerque measured the effect of improvements of the optical properties of receiver surfaces on the performance of flat plate and linear concentrator systems. This activity will be extended by SERI to point focus systems as part of the STDF (Subsystem Technology and Development Facility) component evaluation program. This activity serves to check the reliability of the systems benefit analysis and to gain working experience with advanced absorber surfaces under controlled operating conditions. The first experiments will begin in late FY79.

\subsection{SYSTEMS ANALYSIS}

The systems analysis activity (Figure 3-7) initiated by JPL in FY77 and FY78 will be refined and extended through a joint SERI/JPL effort. Major activities in FY79 will determine the minimum solar absorptance as a criterion in judging intermediate temperature selective absorber development, refine estimates of absorber surface and program cost/benefits, and determine the optimum optical properties for cavity absorbers.

\subsection{DATA BASE}

The data base activity is one part of a larger SERI priority program: the Solar Energy Data Base. The absorber surface portion of the materials data base serves two functions: (1) to make accessible to absorber surface deve1opers and users state-of-the-art information on absorber surface performance, durability, and cost and (2) to provide a resource to the systems analysis and program management activities. The absorber surface data base is divided into materials, system, and local environment sections. The Absorber Surfaces Program will contribute primarily to the materials data base and will utilize the other two sections as resources. It is anticipated that a data synthesis activity, similar to the CINDAS work under Touloukian at Purdue University will be subcontracted for and will be accessible through SERI. An updated bibliography, commercial index, and durability data base will comprise an ongoing SERI activity. The budget of the data base activity is described in Figure 38 .

\subsection{BASIC AND GENERIC RESEARCH}

The Basic and Generic Research activity (Figure 3-9) will emphasize the understanding of degradation mechanisms (thermal, photothermal, environmental) 


\section{Funding for Systems Analysis (\$k)}

Absorber Surfaces Benefit Analysis
A. JPL
B. Sandia-Alb.
C. Sandia-Liv.
D. Refined Benefit Analysis (JPL-SERI)
E. Program Benefit Analysis (SERI)

F. Other Contractors (Boeing, McDonnell Douglas. Martin Marietta, etc.l

TOTAL

\begin{tabular}{|c|c|c|c|c|c|c|}
\hline CY77 & 78 & 79 & 80 & 81 & 82 & 83 \\
\hline FY77 & 78 & 79 & 80 & 81 & 82 & 83 \\
\hline 75 & & & & & & \\
\hline 10 & 5 & & \multicolumn{4}{|c|}{$\begin{array}{l}\text { Decision: Need for Further } \\
\text { Analysis }\end{array}$} \\
\hline 5 & 5 & & & & & \\
\hline & 10 & 60 & & & & \\
\hline 10 & 10 & 10 & & & & \\
\hline 100 & 30 & 75 & & & & \\
\hline
\end{tabular}

Figure 3-7 


\section{Funding for Absorber Surface Data Base (\$\$ $k$ )}

A. Develop/Maintain Data Base (SERI)

B. Data Analysis:'Synthesis

Total

\begin{tabular}{|}
\begin{tabular}{|r|c|c|c|c|c|c|}
\hline CY78 & \multicolumn{2}{|c|}{79} & 80 & 81 & 82 & 83 \\
\hline 10 & 10 & & & & \\
\hline & 35 & & & & \\
\hline 10 & 45 & & & & & \\
\hline
\end{tabular}
\end{tabular}

Figure 3-8 


\section{Funding for Basic and Generic Research (\$k)}

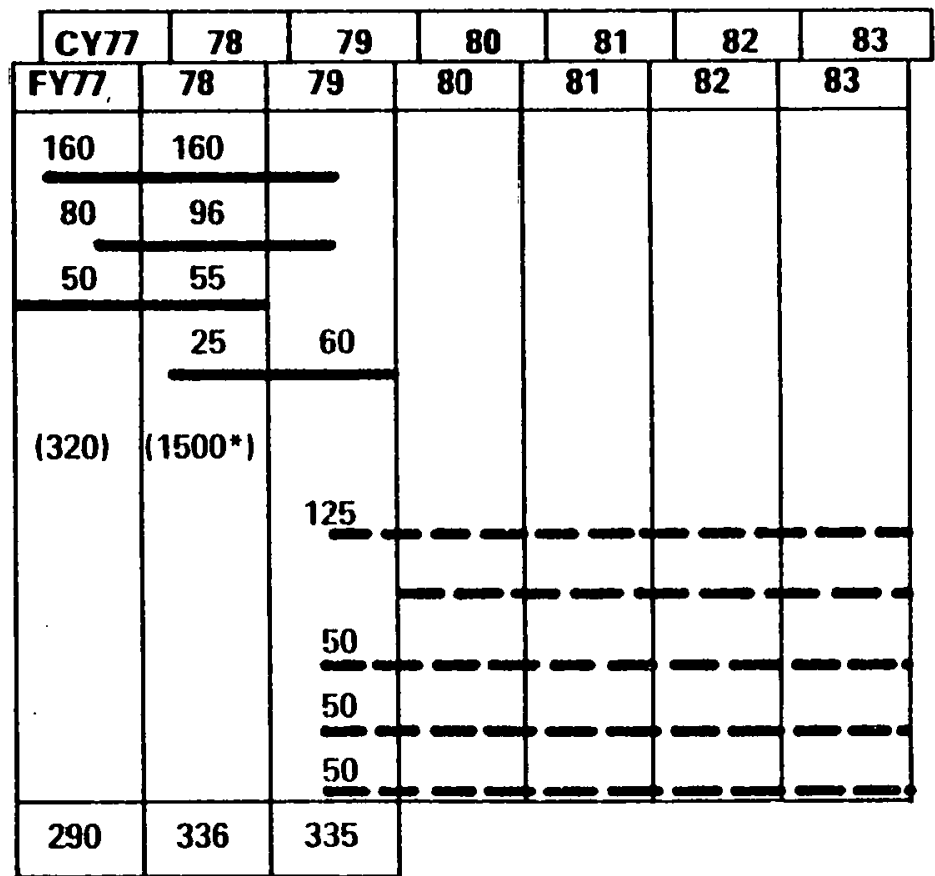

* Photothermal Conversion in FY78 includes amorphous silicon (U. of Arizona, $\$ 100 \mathrm{k}$ ) and amorphous materials (BNL, \$150k). 
and absorber modeling with a small budget reserved for innovative concepts. It is recognized that activities ongoing in DOE/BES will provide a source of information while remaining independent of the Absorber Surfaces Program. 
SECTION 4.0

SERI ABSORBER SURFACE ACTIVITIES

The specific SERI activities that will support the Absorber Surfaces Program are shown in Figure 4-1 with proposed funding levels in FY79. These activities will be performed both in-house and through subcontracts. In addition SERI will manage funds for the development of intermediate- and high-temperature selective and nonselective absorber surfaces. The primary focus of SERI research activity will be the study of photothermal degradation of absorber surfaces leading to improved absorber durability and accelerated lifetime tests. A small research activity has been initiated on electrodeposited black cobalt as a potential selective absorber alternative to black chrome for temperatures greater than $400^{\circ} \mathrm{C}$. This section will elaborate on the degradation, black cobalt, and benefit analysis activities; the remaining support activities listed in Figure 4-1 are described in Section 3.

\subsection{DEGRADATION MECHANISMS}

The present SERI degradation research activity is the study of black chrome under simulated terrestrial environmental exposure. Through a subcontract with Clarkson College black chrome films are prepared by reactive evaporation of chromium onto a substrate in a quartz microbalance. The films are then heated in situ under a controlled environment while the optical properties and the mass of the film are continuously measured. Surface analysis (Auger electron spectroscopy, ESCA, and ion scattering spectroscopy) in combination with depth profiling after the degradation experiment yields further information concerning the mechanisms of degradation. The use of specific isotopes $\left(0^{16}\right.$ or $0^{18}$ ) in the production and degradation of the films is exploited to aid the analysis. This project was begun in June 1978 and will be an 18month effort. An expanded program in degradation research at SERI will begin in FY79.

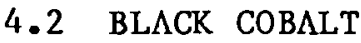

A two-year subcontract with the Colorado School of Mines was started in June 1978 to determine whether electrodeposited black cobalt has suitable solar absorptance, thermal emittance, and thermal/photothermal stability to serve as an absorber coating for receiver applications to $700^{\circ} \mathrm{C}$. Published reports indicate that electrodeposited cobalt oxide has excellent optical properties [33] and extraordinary thermal stability [34]; however, the data presented are preliminary and difficult to evaluate.

The research project will explore the effect of the electrodeposition parameters on the optical performance and photothermal stability of cobalt oxide fi.l.ms. 
Research and Support Activities for Absorber Surfaces (Inhouse and Program Support) (\$k)

SERI Activity

Program Manacement

Annual Conference

Topical Meetings

Quarterly Repouts

Data Base

Field Data Analysis

Benefit Analysis

Measurement Definition and Standards

High Temperature Optical Measurements

Qualification Measurements

Durability Test Definitions

Durability Testing and Component Evaluation

Degradation Mechanisms

Black Cobalt Development

Total

\begin{tabular}{|r|r|}
\hline FY 73 & \multicolumn{1}{|c|}{79} \\
\hline 40 & 80 \\
15 & 10 \\
& 5 \\
& 7 \\
10 & 45 \\
& 25 \\
5 & 60 \\
10 & 25 \\
& 20 \\
& 30 \\
& 70 \\
& 50 \\
25 & 160 \\
25 & 80 \\
\hline 130 & 560 \\
\hline
\end{tabular}

Figure 4-1 


\subsection{BENEFIT ANALYSIS}

Further refinement of the JPL benefit analysis has been initiated jointly by SERI and JPL to assess the effect of off-design operation. The format for this analysis is indicated schematically in Figure 4-2, where lines of constant annualized system efficiency referenced to a good black surface are plotted in the space of the optical parameters of the receiver $\boldsymbol{\alpha}_{s}$ and $\epsilon_{t}$. The selection of model systems has been started and equations to combine collector and heat engine efficiencies into an overall system efficiency are being identified. Site insolation and location will include desert and nondesert climates and low and intermediate latitudes. This analysis will allow the objective determination of program development goals for the optical properties of selective absorbers. 


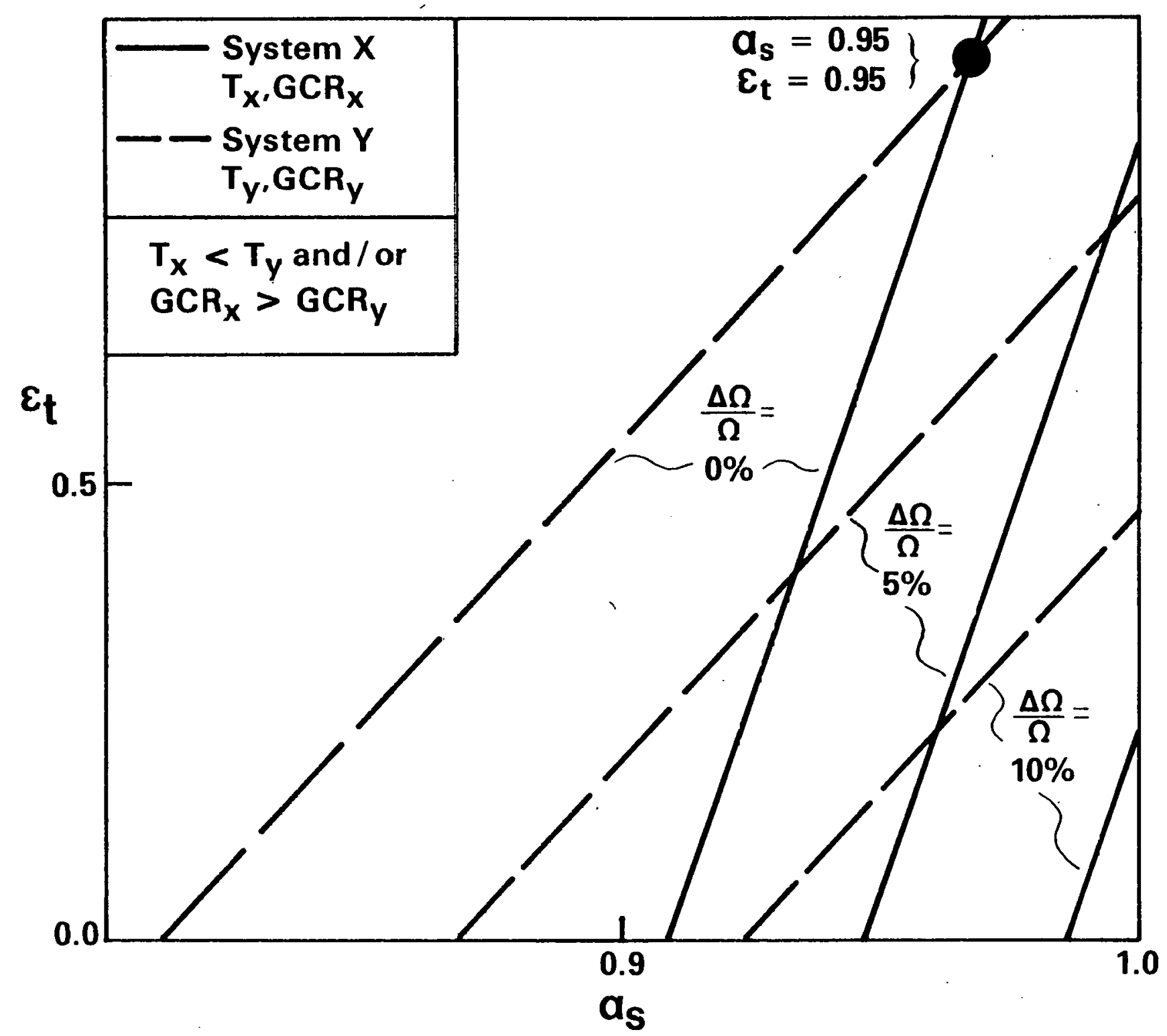

Figure 4-2 Lines of Constant Percentage Improvement of Solar Thermal System Efficiency $(\Delta \Omega / \Omega)$ as a Function of Absorber Surface Optical Properties Relative to a Good Non-Selective Surface $\left|a_{s}=0.95, \varepsilon_{t}=0.95\right|$ 


\section{SECTION 5.0}

\section{REFERENCES}

1. Adams, M. A., Carrol1, W. F., Reeve, R. T., and Zeldin, B., "A Methodology for Assessing the Benefits of Absorber Coatings for Solar/Thermal Receivers," Proceedings of DOE/DST Thermal Power Systems Workshop on Selective Absorber Coatings, Golden, Colorado, December $\overline{1977}, \overline{396},(1978)$.

2. Tabor, H., "Selective Radiation; Wavelength Discrimination," Conference on the Use of Solar Energy, Tucson, Arizona, November $1955,2,(1956)$.

3. Hahn, R.E. and Seraphin, B.0., "Spectrally Selective Surfaces for Photothermal Solar Energy Conversion", Physics of Thin Films Vol. 10, Academic Press, New York (1978).

4. Seraphin, B.0. and Meinel, A.B., "Photothermal Solar Energy Conversion and the Optical Properties of Solids," Chap. 17 in Optical Properties of Solids New Developments, North Holland, Amsterdam (1978).

5. Proceedings of the Symposium on Materials Science Aspects of Thin Films in Solar Energy Conversion, Tucson, Arizona, May 1975 (NSF-RANN Report GI-43795).

6. Proceedings of the Symposium on Fundamental Optical Properties of Solids Relevant to Solar Energy Conversion, Tucson, Arizona, Nov. 1975 (NSF Report DMR-75-18134).

7. Proceedings of the Workshop on Surface Coatings, Minneapolis, Minnesota, July 1975 (ERDA Re port E[04-3]-1101).

8. Proceedings of DOE/DST Thermal Power Systems Workshop on Selective Absurber Coatings, Golden, Colorado, December 1977 (SERI Report TP-3I-061).

9. Mattox, D.M., Kominiak, G. J., Sowell, R. R. and Pettit, R. B., "Selective Solar Photothermal Absorbers," Sandia Laboratories, Report SAND 75-0361 (1975).

10. Melamed, L. and Kaplan, G. M., "Survey of Selective Absorber Coatings for Solar Energy Technology," Journal of Energy. 1, 100 (1977).

11. R. Sowell, private communication. To be published in Plating and Surface Finishing.

12. Grimmer, D., "Solar Selective Absorber Coatings on Glass Substratee," L $\Lambda$-UR-77-2700 (1977). 
13. Data from Optical Coating Laboratory, Inc., (OCLI), 2789 Giffen Avenue, Santa Rosa, California 95403.

14. Tempil Corporation, Hamilton Boulevard, South Plainfield, New Jersey.

15. Tobin, R., "Absorptive Coatings Evaluation for Solar Tower Receiver Applications," p. 73, Proceedings of DOE/DST Thermal Power Systems Workshop on Selective Absorber Coatings, Golden, Colorado, December 1977 (SERI Report TP-31-061).

16. "Thermal Radiative Properties of Coatings," Vol. $\underline{9}$, in Thermophysical Properties of Matter, ed. Y. S. Touloukian. Plenum Data Corporation, New York (1972).

17. Lin, R. J. H., and Zimmer, P. B., "Optimization of Coatings for Flat Plate Solar Collectors," Phase II Final Report, July 1977 (DOE Contract EY-76-02-2930000).

18. Masterson, K., "Selective Surfaces for Solar Thermal Conversion," Journal of Solid State Chemistry, 22, 41 (1977).

19. Treadwell, G., "Design Considerations for Parabolic Cylindrical Solar Collectors," Sandia Laboratories Report SAND 76-0082 (1976).

20. Abrams, M., "The Effectiveness of Spectrally Selective Surfaces for Exposed, High-Temperature Solar Absorbers," SAND $77-8300$ ( 1978$)$.

21. Simon, F., "Flat-P1aLe Solar Collector Performance Evaluatinn with a Solar S1mulalur as a Basis for Collector Selection and f'uiluimance Prcdictlul," NASA Tochniral Mrmnrandim. NASA TMX71793 (1975).

22. Knoll, R. H. and Johnson, S. M., "Baseline Performance of Solar Collectors for NASA Langley Solar Building Test Facility," NASA Technical Memorandum, NASA TMX-3505 (1977).

23. Spitz, J., private communication of work performed at Centre d'Etude Nucleaire Grenoble.

24. Treadwell, G. W., McCulloch, W. H., and Rusk, R. S., "Test Results from a Parabolic-Cylindrical Solar Collector," Sandia Laboratories Report, SAND 75-5333 (1975).

25. Wen, L. and Caputo, R., "Effects of Surface Optical Characteristics on Point Focusing Solar Collectors," p. 369, Proceedings of DOE/DST Thermal Power Systems Workshop on Selective Absorber Coatings, Golden, Colorado, December $19 \overline{77}$ (SERI Report TP-31-061). 
26. Wen, L. and Caputo, R., "Increasing Geometric Concentration Ratio Vs. Improving Receiver Surface Characteristics for Selected Solar Thermal Collectors," JPL Report, JPL 5102-63 (1978).

27. JPL/NASA-Lewis Research Center, "Absorber Surface Materials Program Plan," June 21, 1977.

28. "Solar Energy: A Status Report," DOE/ET-0062, June 1978.

29. Brown, K. C., "Solar Systems for Industrial Process Heat," Chapter XX, CRC Handbook, Economics of Energy Conservation, F. Krelth, ed., ro be published.

30. Ergenics, Division of MPD Technology Corporation, 4 William Demarest Place, Waldw1ck, New Jersey 07463.

31. Fourth Annual Report, The University of Sydney, Energy

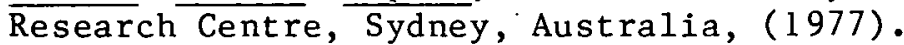

32. National Program Plan for R\&D in Solar Heating and Cooling of Buildings, Agricultural and Industrial Applications, DOE/CS0008, (Aug. 1978).

33. van der Leij, M., "Investigation and Perspectives on Iron Oxide, Zinc Conversion Coatings, Zinc Oxide, Cobalt Oxide and Tungsten Oxide as Spectral Selective Solar Absorber Surfaces," Paper 非0059, Session 31-1, Deh1i, ISES-Congress, 1978.

34. Kokoropoulos, P., Salam, E., and Daniels, F., "Selective Radiation Coatings Preparation and High Temperature Stability," Solar Energy 3 , 19 (1959). 


\section{Distribution}

Departinent of Energy:

Attn: DOE, $\cdot$ SERI Site Office

Contracting officer

Charles M. Skinner

Chicago Operations office

Interim Program Division

Attn: M. E. Jackson

1

Division of Solar Technology

Office of Asst. Director for Administration

Attn: R. H. Annan

2

nffire of Asst. Socrotary for

Conservation \& Solar Applications

Attn: R. Scott

1

Office of Solar, Geothermal, Electric \& Storage Programs

Attn: H. H. Marvin

2

Division of Energy Technology

Administration

Attn: S. Hansen

1

Division of Distributed Solar

Technology

Office of the Director

Attn: R. San Martin

1

Division of Central Solar

Technology

Office of the Director

Attn: H. Coleman

1

Division of Energy Storage Systems

Office of the Director

Attn: G. Pezdirtz

1

Divisinn of Planning \& Energy Trancfer

Office of the Director

Attn: M. Adams 